University of Florida Levin College of Law

UF Law Scholarship Repository

Faculty Publications

Faculty Scholarship

5-3-2013

\title{
Humane Punishment for Seriously Disordered Offenders: Sentencing Departures and Judicial Control over Conditions of Confinement
}

\author{
E. Lea Johnston
}

University of Florida Levin College of Law, johnstonl@law.ufl.edu

Follow this and additional works at: http://scholarship.law.ufl.edu/facultypub

Part of the Criminal Law Commons, and the Criminology Commons

\section{Recommended Citation}

Johnston, E. Lea, "Humane Punishment for Seriously Disordered Offenders: Sentencing Departures and Judicial Control over Conditions of Confinement" (2013). Faculty Publications. Paper 246.

http://scholarship.law.ufl.edu/facultypub/246 
*DRAFT: PLEASE DO NOT CITE WITHOUT PERMISSION

MAY 3, 2013

\title{
Humane Punishment for Seriously Disordered Offenders: Sentencing Departures and Judicial Control over Conditions of Confinement
}

\author{
E. Lea Johnston*
}

\begin{abstract}
$\underline{\text { Abstract }}$
At sentencing, a judge may foresee that an individual with a major mental disorder will experience serious psychological or physical harm in prison. In light of this reality and offenders' other potential vulnerabilities, a number of jurisdictions currently allow judges to treat undue offender hardship as a mitigating factor at sentencing. In these jurisdictions, vulnerability to harm may militate toward an order of probation or a reduced term of confinement. Since these measures do not affect offenders' day-to-day experience in confinement, these expressions of mitigation fail to protect adequately those vulnerable offenders who must serve time in prison. This Article argues that judges should possess the authority to tailor the conditions of vulnerable, disordered offenders' carceral sentences to ensure that sentences are humane, proportionate, and appropriate for serving the intended aims of punishment. To equalize, at least in part, conditions of confinement for this population, judges should consider ordering timely and periodic mental health evaluations by qualified professionals, disqualifying facilities with insufficient mental health or protective resources, specifying the facility or unit where an offender will serve or begin his sentence, and mandating certain treatment in prison. Allowing judges to exercise power over correctional conditions in this way will allow judges to fulfill better their institutional function of meting out appropriate, humane, and proportionate punishments, subject prison conditions to public scrutiny and debate, and help reform the image and reality of the criminal justice system for some of society's most vulnerable individuals.
\end{abstract}

\footnotetext{
* Associate Professor of Law, University of Florida, Levin College of Law. I wish to thank Miriam Baer, Douglas Berman, Darryl Brown, Michael Cahill, Mary Anne Franks, Jerold Israel, Elta Johnston, Wes Jones, Shani King, Jennifer Laurin, Tom Lin, Jason Nance, Sharon Rush, Michael Seigel, Christopher Slobogin, John Stinneford, and Scott Sundby for their valuable comments and suggestions. I also appreciate feedback from participants at the University of Florida Levin College of Law's Criminal Justice Center's Junior Scholars' Conference. I am grateful for the summer grant provided by the Levin College of Law. Finally, I thank Laura Beard, Rebecca Eikleberry, Jessie Ervolino, Matt Michel, Patricia Morgan, Erica Perdomo, Nerissa Robinson, Daniel Tullidge, Christopher Vallandingham, and Benjamin Wolf for their outstanding research assistance.
} 
*DRAFT: PLEASE DO NOT CITE WITHOUT PERMISSION

MAY 3, 2013

\section{Table of Contents}

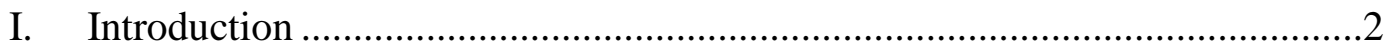

II. Identification and Treatment of Serious Mental Illnesses in Prison ................7

A. Mental Health Screen ..................................................................7

B. Shortcomings in Initial Screening Procedure..............................10

C. Treatment, Housing, and Vulnerability.....................................15

III. Legitimacy of Recognizing Vulnerability to Harm at Sentencing .................24

A. Retributive Rationales ...........................................................25

B. Rehabilitative Rationales........................................................29

C. Collateral Benefits ................................................................31

IV. Jurisdictions' Current Treatment of Vulnerability as a Mitigating Factor .....32

V. Sentencing as a Means to Flag Offenders with Serious Mental Disorder......36

A. Relative Accuracy of Judicial Findings of Mental Disorder........37

B. Comparison to Guilty But Mentally Ill Verdict ...........................42

VI. Sentencing as a Means to Equalize Conditions of Confinement....................43

A. Authority to Disqualify Certain Facilities .................................47

B. Authority to Designate Certain Facility ...................................48

1. Intermediate Care Facilities..................................................49

2. Benefits of Initial Facility Designation ..................................53

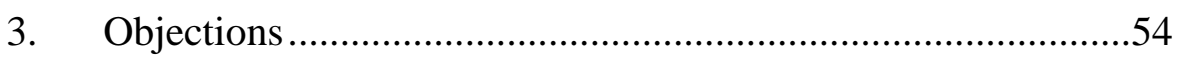

C. Authority to Mandate Certain Treatment Consequences ..............55

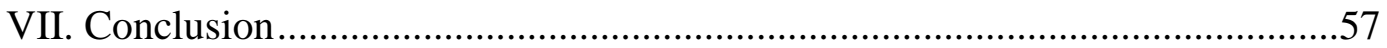

\section{Introduction}

Prisons are overwhelmed with inmates with schizophrenia, bipolar disorder, and other serious mental illnesses, who are ill-equipped to navigate these dangerous environments. ${ }^{1}$ Some individuals, because of their major mental

\footnotetext{
${ }^{1}$ Experts estimate that around $16 \%$ of prisoners have a mental disorder. See Kenneth Adams \& Joseph Ferrandino, Managing Mentally Ill Inmates in Prisons, 35 CRIM. JustiCE \& BeHAV. 913, 913 (2008) ("Although specific estimates vary depending on the research methodology and definition of mental illness used, the proportion of mentally ill prison inmates is generally estimated to be around $16 \%$, based on mental health service records.”) (internal citations omitted); Morris L. Thigpen et Al., EfFective Prison Mental Health Services (National Institute of Corrections 2004), available at http://nicic.gov/Library/018604 (discussing studies). This rate exceeds the incidence of mental disorder within the community. See DORIS J. JAMES \& LAUREN E. Glaze, Mental Health Problems of Prison and Jail Inmates 3 (Bureau of Justice Statistics 2006), available at http://bjs.ojp.usdoj.gov/content/pub/pdf/mhppji.pdf (reporting that about $11 \%$ of persons age 18 or older in the U.S. general population satisfy DSM-IV criteria for symptoms of
} 
*DRAFT: PLEASE DO NOT CITE WITHOUT PERMISSION

MAY 3, 2013

disorders and other vulnerabilities, ${ }^{2}$ will experience serious psychological and physical harm when imprisoned, and judges can anticipate these harms at sentencing. ${ }^{3}$ The hazards faced by seriously disordered inmates are numerous and substantial. Correctional officials may fail to detect an inmate's disorder ${ }^{4}$ or treat it effectively. ${ }^{5}$ Typically housed within the general prison population, inmates with major mental disorders are especially likely to suffer physical and sexual victimization. ${ }^{6}$ For disciplinary or protective reasons, correctional officials are disproportionately likely to transfer disordered inmates to solitary confinement, ${ }^{7}$

a mental health disorder). Since male prisoners constitute 93\% of the prisoner population in the United States, this Article will focus on male prisoners. See Heather C. West, et al., Prisoners in 2009, U.S. Dept. of Justice, Office of Justice Programs, Bureau of Justice Statistics, available at http://bjs.ojp.usdoj.gov/content/pub/pdf/p09.pdf.

2 The focus of this Article is on individuals with serious mental illnesses who receive sentences of imprisonment. A defendant's mental disorder may not be his only source of vulnerability to serious harm in prison, however. See infra notes 6 \& 151. Any additional sources of vulnerability should also factor into a sentencing calculus to ensure that sentences are humane, proportionate, and serve other intended aims of punishment.

${ }^{3}$ See, e.g., United States v. Boutot, 480 F. Supp. 2d 413, 419, 421 (D. Me. 2007) (granting a downward departure because the court was "concerned about the impact that serving a prison term with the general inmate population would have” on the defendant, who was prone to mental decomposition when not adequately treated); United States v. Roach, No. 00 CR 411, 2005 WL 2035653, at*6-8 (N.D. Ill. Aug. 22, 2005) (finding "that[,] absent continuing and appropriate psychotherapy, [the defendant] will be placed at significant risk of a relapse to serious depression, placing her at risk of suicide ... ., and thus reducing the defendant's sentence under 18 U.S.C. $\S 3553($ a) to allow for treatment); United States v. Ribot, 97 F. Supp. 2d 74, 84 (D. Mass. 1999) (granting a downward departure, under U.S.S.G. $\S \S 5 \mathrm{H} 1.3$ and 5K2.13, in part because "sending [the defendant] to prison would aggravate his major depressive disorder with potentially life threatening consequences" and emphasizing the defendant's twenty-five year struggle with depression and prior suicide attempt); People v. Zung, 531 N.Y.S.2d 615, 615-16 (N.Y. App. Div. 1988) (substituting the punishment of imprisonment for community service in part because "uncontroverted medical documents indicate that a period of incarceration would be severely detrimental to this defendant's mental health, and could possibly exacerbate his suicidal tendencies”); People v. Jackson, Nos. 282708, 284430, 2009 WL 1361956, at *3 (Mich. Ct. App. May 14, 2009) (upholding the lower court's reduction of the defendant's sentence based, in part, on "her suicidal ideations").

${ }^{4}$ See infra notes 41-54 and associated text.

${ }^{5}$ See infra notes 73-131 and associated text.

${ }^{6}$ See infra note 93. Additional risk factors may also place individuals at heightened risk. Other risk factors for sexual abuse within correctional facilities include physical or developmental disability; youth; diminutive size; a history of victimization; first, nonviolent, or sexual offender status; and perception as gay, bisexual, transgender, or gender-nonconforming. See Section 115.41, Docket No. OAG-131 (signed May 16, 2012) (to be codified at 28 C.F.R. pt. 115), www.ojp.usdoj.gov/programs/pdfs/prea_final_rule.pdf (identifying risk factors for sexual assault in prison); see also NATIONAL RAPE ELIMINATION COMMITTEE REPORT 7-8, 69-74 (June 2009), https://www.ncjrs.gov/pdffiles1/226680.pdf (discussing risk factors).

${ }^{7}$ See infra note 95. 
*DRAFT: PLEASE DO NOT CITE WITHOUT PERMISSION

MAY 3, 2013

where they often experience serious psychological deterioration and acute distress. ${ }^{8}$ The occurrence of these foreseeable harms threatens to undermine the intended purposes of an offender's punishment and render his sentence disproportionate or even inhumane.

Cognizant of this reality, a number of jurisdictions allow a judge to depart from a presumptive sentence when an offender would face excessive or undue hardship in prison. ${ }^{9}$ Some states allow a finding of likely hardship to support a stayed sentence of incarceration with probation, ${ }^{10}$ while other jurisdictions allow a judge to reduce the duration of an offender's term of confinement on this basis. ${ }^{11}$ These measures, in effect, allow courts to impose different penalties on offenders in order to achieve punishments of similar punitive bite. ${ }^{12}$ These practices expose jurisdictions to charges of undermining the value of parity in punishment for equally blameworthy offenders and the reliability of the sentencing process. Further, these efforts do not provide adequate relief for those offenders who do not qualify for probation, despite their substantial risks of serious harm if incarcerated. Thus, the efforts of states and the federal government to date, while laudable, are at best incomplete.

Responsive to these concerns, an alternative means of recognizing vulnerability would be to provide the same basic punishment to vulnerable defendants as to standard offenders, but in a form designed to remove the unacceptable hardships that flow from an offender's disability. To accomplish this objective, a judge could order the term of incarceration established by the legislature as the deserved penalty for a given offense, but then attach certain conditions to help ensure that the prison experience of the vulnerable offender will match in severity that of a standard offender. Unfortunately, judges currently lack the means to condition the carceral sentences of vulnerable offenders in this way.

This Article proposes an expansion of judicial authority to protect vulnerable offenders with serious mental illnesses and to effectuate the legitimate aims of punishment. In particular, the Article urges legislatures to authorize

\footnotetext{
${ }^{8}$ See infra note 96.

${ }^{9}$ Specific authorization is most critical in jurisdictions that channel or limit judges' discretion at sentencing. About half of all states employ indeterminate sentencing schemes that allow for wide judicial discretion, while remaining jurisdictions limit judges' abilities to vary sentences according to offender characteristics through sentencing guidelines or a statutory determinate sentencing regime. See Kevin R. Reitz. The New Sentencing Conundrum: Policy and Constitutional Law at Cross-Purposes, 105 Colum. L. REv. 1082, 1102-03 (2005).

${ }^{10}$ See infra notes 173-175 and accompanying text.

${ }^{11}$ See infra notes 177-180 and accompanying text.

${ }^{12}$ See E. Lea Johnston, Vulnerability and Just Desert: A Theory of Sentencing and Mental Illness, 103 J. CRIM. L. \& CRIM. 145, 216-21 (2013).
} 
judges to ameliorate unacceptably high risks of serious harm to seriously disordered offenders by tailoring individual sentences of confinement. ${ }^{13}$ With this power, a judge, through a sentencing order, could positively intervene in a seriously disordered offender's prison experience at two crucial junctures. First, a judge could ensure that an inmate receives a comprehensive mental health evaluation by a qualified mental health professional at intake. This would increase the probability that correctional officials would recognize an offender's mental disorder and provide necessary treatment. Second, a judge could include restrictions within an offender's sentence to reduce the likelihood of the inmate's degeneration or victimization in prison. These conditions could include disqualifying sites of confinement that lack certain mental health resources, barring disciplinary options known to exacerbate mental disorder, or requiring an inmate to start his sentence in an available residential treatment unit. These interventions not only would potentially safeguard vulnerable, seriously disordered offenders but also would allow judges better to achieve their key objective of meting out appropriate, humane punishments for individuals' criminal offenses.

Critically, this Article limits its attention to defendants with Axis I mental disorders. ${ }^{14}$ Many other risk factors exist and merit recognition, ${ }^{15}$ but major mental disorders pose unique difficulties within prisons. First, individuals with serious mental illnesses face the specific threat of loss of cognitive function, which-because it implicates a defendant's hold on reality, personality, and autonomy - is a particularly acute interest. Second, mental disorder is often hard to diagnose, and the nature of the screening system employed at prison intake centers means that some individuals' disorders will be overlooked, leading to a

${ }^{13}$ Sentencing constitutes one of those "zones of twilight” in which the distribution of power between the separate branches of government overlaps and is uncertain. See Jordan Fried, The Constitutionality of the U.S. Sentencing Commission: An Analysis of the Role of the Judiciary, 57 GEO. WASH. L. REV. 704, 712-13 (1989) (quoting Youngstown Sheet \& Tube Co. v. Sawyer, 343 U.S. 579, 637 (1952)); see also Mistretta v. United States, 488 U.S. 361, 364 (1989) ("Historically, federal sentencing-the function of determining the scope and extent of punishment-never has been thought to be assigned by the Constitution to the exclusive jurisdiction of any one of the three Branches of Government. Congress, of course, has the power to fix the sentence for a federal crime, and the scope of judicial discretion with respect to a sentence is subject to congressional control.”).

14 Axis I disorders, as defined by the American Psychiatric Association, include clinical syndromes such as schizophrenia, bipolar disorder, and depression, as well as chronic brain diseases that cause extreme distress and interfere with social and emotional adjustment. See AM.

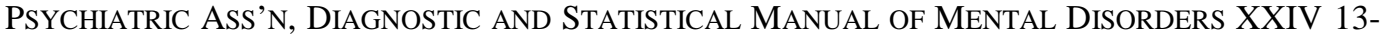
24, 28 (4th ed. rev. 2000) ("DSM-IV-TR"). In this paper, serious mental illness, major mental illness, major mental disorder, and Axis I disorder are used interchangeably.

${ }^{15}$ See supra note 6 (detailing risk factors). 
delay in treatment and placement in an unsuitable environment. ${ }^{16}$ Other vulnerabilities, such as diminutive stature, physical disability, or first-offender status, may be easier to identify (and harder to feign). ${ }^{17}$ Third, prisons commonly protect offenders vulnerable to abuse by placing them in protective custody or solitary confinement, though most mental health experts and some courts agree that confining offenders with serious mental illnesses in these conditions poses a strong likelihood of severe psychological damage. ${ }^{18}$ To the extent that isolation is used for safeguard, prisons may lack a means of protecting vulnerable offenders with major mental disorders in a way that does not further endanger their health. Finally, insofar as the inadequate care and treatment of prisoners with serious mental disorders originates from a lack of information about the presence of disorder and benign neglect in prisons, judges may be able to compensate partially for these deficiencies through sentencing.

To be clear, this Article does not advocate for judges to assume responsibility for evaluating and placing mentally ill inmates or for a diminution of correctional responsibility in these areas. Indeed, prisons are well positioned for, and should accelerate their progress in, developing and implementing objective, verified, reliable classification procedures and humane housing and treatment options for mentally ill offenders. ${ }^{19}$ Rather, the Article merely examines whether a judge - when he finds that an offender with a serious mental disorder must be incarcerated for his criminal offense but is concerned that incarceration poses an unacceptable risk of serious harm to that offender-should be authorized to shape the offender's sentence to minimize its harmful potential.

This Article is organized in seven parts. Part II identifies the potential perils that await an offender with serious mental illnesses in prison, including shortcomings in the processes designed to detect offenders' mental disorders and provide protective and therapeutic housing. Recognizing that correctional agencies rightfully consider offender vulnerability at multiple stages in the classification process, Part III defends the premise that vulnerability is also a legitimate source of concern for sentencing judges in order to effectuate various aims of punishment. Part IV details jurisdictions' current approaches to recognizing undue hardship in sentencing and explains why these approaches are inadequate for those vulnerable offenders who must be imprisoned, given the nature of their crimes or their criminal histories. Part V explores the extent to which judges' findings of mental disorder could prevent offenders' disorders from slipping undetected through the prison admission process. In this way, judges'

${ }^{16}$ See infra notes 41-72 and accompanying text.

${ }^{17}$ This observation does not apply to all vulnerabilities to serious harm in prison, such as gay or bisexual orientation. See supra note 6.

${ }^{18}$ See infra notes 95-104 and accompanying text.

${ }^{19}$ See infra note 100 and accompanying text. 
*DRAFT: PLEASE DO NOT CITE WITHOUT PERMISSION

MAY 3, 2013

sentencing orders could assume a functionality similar to the controversial guilty but mentally ill verdicts available in some states. Finally, Part VI draws from existing state experience to investigate possible conditions that judges could attach to the sentences of seriously disordered offenders in order to render vulnerable offenders' sentences more proportionate and humane. These conditions could include disqualifying facilities particularly likely to exacerbate an individual's disorder, designating facilities with certain treatment or protective options, and mandating that offenders receive-or not receive-certain treatment in prison.

\section{Identification and Treatment of Serious Mental Illnesses in Prison}

Prison is physically and psychologically hazardous for inmates with major mental disorders. Recognizing the constitutional imperative to identify and treat these offenders, ${ }^{20}$ the vast majority of prisons have established procedures to detect serious mental health issues at intake and factor an inmate's mental health needs into his facility and housing placements. Shortcomings exist in the current assessment and classification systems, however, that lead to the under-detection of mental disorder and unpredictable placement in protective housing. In addition, the protective housing options afforded by many prisons can actually exacerbate mental disorder. The following sections offer a study and critique of the processes in place to screen individuals for mental illnesses, and the treatment and housing options available in prisons for vulnerable and mentally disordered prisoners.

\section{A. Mental Health Screen}

Prisons rely on a triage system to identify offenders with mental disorders who require treatment and special housing. ${ }^{21}$ The initial mental health screensometimes the only assessment of an inmate's mental health-is typically part of the prison intake process. ${ }^{22}$ The aims of this screen are to detect individuals with severe mental disorders who need immediate psychiatric attention, prevent

\footnotetext{
${ }^{20}$ See infra notes 73-77 and accompanying text.

${ }^{21}$ See Allen J. Beck \& Laura M. MaruschaK, Mental Health Treatment in State PRISONS, 2000 1-2, 5 (Bureau of Justice Statistics 2001), available at http://www.bjs.gov/index.cfm?ty=pbdetail\&iid=788; NATIONAL INSTITUTE OF CORRECTIONS, Provision OF MENTAL HEALth CARE IN PRISONS 2 (2001), available at http://static.nicic.gov/Library/016724.pdf; Humberto Temporini, Conducting Mental Health Assessments in Correctional Settings, in HandBook of Correctional Mental Health 119, 129-39 (Charles L. Scott, ed., 2d ed. 2010).

${ }^{22}$ See BECK \& MARUSCHAK, supra note 21, at 2. For a detailed treatment of the variety of approaches to the intake process employed by state correctional agencies, see PATRICIA L. HARdyman et AL., Prisoner InTAKe Systems: AsSEssing NEEdS AND ClasSifying PRISONERS (Nat'l Institute of Corrections 2004), http://static.nicic.gov/Library/019033.pdf [hereinafter HARDYMAN ET AL., PRISONER INTAKE SYSTEMS].
} 
suicide, continue individuals' psychotropic medications, and identify individuals with non-acute mental health needs that require further assessment and treatment. ${ }^{23}$ In addition, the results of the mental health screen inform an inmate's classification, housing, job assignments, programming, and treatment. ${ }^{24}$ The screen typically consists of a short interview regarding an inmate's current symptoms, past psychiatric history, suicide potential, social history, and educational history. ${ }^{25}$ It also may involve a review of available records and the administration of specialized instruments or tests. ${ }^{26}$

If the evaluator believes an inmate is likely to have one or more psychiatric disorders, he will refer the inmate to a mental health professional for further evaluation and testing. ${ }^{27}$ This "second-level triage" 28 should, according to guidelines issued by the American Psychiatric Association, take place within 72 hours of referral and consist of a "brief mental health assessment" tailored to "the particular, suspected level of services needed." ${ }^{29}$ Finally, for inmates with serious treatment needs, a psychiatrist or other appropriately credentialed mental health professional should perform a comprehensive mental health evaluation within a time frame appropriate to the level of urgency. ${ }^{30}$ This thorough evaluation consists of a face-to-face interview and a review of health care records and collateral information. ${ }^{31}$ It usually concludes with a diagnostic formulation and an initial treatment plan. ${ }^{32}$

${ }^{23}$ See Temporini, supra note 21, at 130, 135.

${ }^{24}$ HARDYMAN ET AL., PRISONER INTAKE SySTEMS, supra note 22, at 10-11.

${ }^{25}$ Id. at 10; Temporini, supra note 21, at 135.

${ }^{26}$ See ThigPen ET AL., supra note 1, at 14; HARDYMAn ET AL., PRISONER INTAKE Systems, supra note 22, at 10 ("Generally, the screen consists of a brief interview by mental health staff. Depending on the results, the mental health staff may complete one or more psychological tests, such as the Millon Clinical Multiaxial Inventory (MCMI), the Minnesota Multiphasic Personality Inventory (MMPI), and the Wechsler Adult Intelligence Scale (WAIS).”).

27 Temporini, supra note 21, at 135-36; THIGPEN ET AL., supra note 1, at 14 ("A more elaborate and comprehensive evaluation or assessment should take place for those identified by the screening process as likely to have one or more psychiatric disorders.”); NATIONAL INSTITUTE OF CORRECTIONS, supra note 21, at 2 ("Inmates identified as needing additional mental health assessment are then referred to psychologists, psychiatrists, or a mental health team for a further evaluation of their needs and assignment to housing and services.”); HARDYMAN ET AL., PRISONER INTAKE SYSTEMS, supra note 22, at 10.

${ }^{28}$ Temporini, supra note 21, at 139.

${ }^{29}$ AMERICAN Psychiatric Association, Psychiatric SERVICES IN JAILS AND Prisons 4344 (2d ed. 2000).

${ }^{30} \mathrm{Id}$. at 44 .

${ }^{31} \mathrm{Id}$.

${ }^{32} I d$. 
*DRAFT: PLEASE DO NOT CITE WITHOUT PERMISSION

MAY 3, 2013

While inmates who screen positive for mental disorder will receive additional assessment, few safety nets exist for those assessed as having no cognizable mental health problem at the initial screening point. Human rights advocates report, "In many prisons, there is no routine monitoring of [the] mental health of prisoners who are not on [the] mental health caseload, even when the prisoners are in notoriously stressful settings such as segregation that can prompt mental health crises.” ${ }^{33}$ Legal commentators have urged prisons to conduct a subsequent screen to catch inmates whose disorders are not detected or who develop mental health problems during the course of their confinement, ${ }^{34}$ but prisons typically do not conduct a second screen for all inmates. ${ }^{35}$ Rather, prisons rely on post-classification referral to detect mental health disorders that manifest after admission. ${ }^{36}$ Anecdotal evidence suggests that the referral process is woefully deficient, ${ }^{37}$ however, as seriously ill inmates will often not self-report ${ }^{38}$ and correctional officers tend to misinterpret symptomatic illness as disorderly conduct and report only inmates who pose security threats. 39 "As a consequence,"

33 Human Rights WATCh, Ill-Equipped: U.S. PRisons AND OfFEndERS With MentAL ILLNESS 102 (2003).

${ }^{34}$ See Bonnie J. Sultan, The Insanity of Incarceration and the Maddening Reentry Process: A Call for Change and Justice for Males with Mental Illness in United States Prisons, 13 GEO. J. ON POVERTY L. \& POL’y 357, 374 (2006) (“[A]ll [persons currently incarcerated] should be reevaluated at a later date during their incarceration, since mental illness can develop inside prison.”).

35 See HUMAN Rights WATCH, supra note 33, at 101 ("Prisoners with mental illness are not identified upon entry into prison and are left untreated.”); infra note 36.

36 See Temporini, supra note 21, at 137-38; NATIONAL INSTITUTE OF CORRECTIONS, supra note 21, at 137-38 (describing the process of post-classification referral).

37 See, e.g., HUMAN RigHTS WATCH, supra note 33, at 101 (warning that the current system fails to identify and treat in a timely manner prisoners who develop mental disorders after admission); Richard L. Elliott, Evaluating the Quality of Correctional Mental Health Services: An Approach to Surveying a Correctional Mental Health System, 15 BEHAV. SCI. \& L. 427, 435 (1997) (identifying a number of elderly prisoners with serious, persistent mental illness who had not been diagnosed as such and were not currently receiving mental health treatment).

${ }^{38}$ Madrid v. Gomez, 889 F. Supp. 1146, 1218 (N.D. Cal. 1995) ("While mentally competent inmates can be relied upon to self-report most medical ailments, mentally ill prisoners may not seek out help where the nature of their mental illness makes them unable to recognize their illness or ask for assistance.”).

${ }^{39}$ See W. David Ball, Mentally Ill Prisoners in the California Department of Corrections and Rehabilitation: Strategies for Improving Treatment and Reducing Recidivism, 24 J. CONTEMP. HEALTH L. \& POL’y 1, 16-17 (2007); HUMAN RIGHTS WATCH, supra note 33, at 75-76 (relaying officers' disclosure that mental health referrals would often be made for disruptive, but not merely bizarre, behavior); Jamie Fellner, A Corrections Quandary: Mental Illness and Prison Rules, 41 HARV. C.R.-C.L. L. REV. 391, 396 (2006) ("Officers typically do not understand the nature of mental illness and its behavioral impact. They cannot distinguish-and may not even know a distinction exists-between a frustrated or disgruntled inmate who 'acts out' and one whose 
*DRAFT: PLEASE DO NOT CITE WITHOUT PERMISSION

MAY 3, 2013

one court observed, "custody staff essentially make medical judgments that should be reserved for clinicians, and some inmates are not given appropriate early treatment that could prevent or alleviate a severe psychiatric disorder." 40

\section{B. Shortcomings in Initial Screening Procedure}

Multiple shortcomings mar correctional agencies' mental health screening processes. Some deficiencies involve failures in implementation, while other problems are structural in nature.

First, while the vast majority of prison facilities report administering mental health screens within a day of admission, ${ }^{41}$ they may not do so in a comprehensive manner or under conditions likely to generate accurate results. For instance, in Coleman v. Wilson, the U.S. District Court for the Eastern District of California found, "The [mental health screening] mechanisms on which [the California Department of Corrections] rely are either used haphazardly, or depend for efficacy on incomplete or non-existent medical records, self-reporting, or the observations of custodial staff inadequately trained in the signs and symptoms of mental illness." 42 The court concluded: "The evidence before the court plainly shows that thousands of inmates suffering from mental illness are either undetected, untreated, or both."43 Despite the existence of a court order to improve the assessment process, ${ }^{44}$ the U.S. District Court for the Northern District of California found in 2005 that "the reception center intake process . . . fails to

'acting out' reflects mental illness. They assume misconduct is volitional or manipulative.”); Johnston, Vulnerability, supra note 12, at 169-74.

${ }^{40}$ Madrid, 889 F. Supp. at 1219.

${ }^{41}$ See James Austin \& Kenneth McGinnis, ClAssification OF High-Risk and Special Management Prisoners: A National Assessment of CuRrent Practices 45 (Nat'l Institute of Corrections 2004), http://static.nicic.gov/Library/019468.pdf (Exhibit 16) (Showing that 100\% of responding states screened male inmates for suicide risk and psychotic and mood disorders at the initial assessment while $84 \%$ do so for personality disorders); HARDYMAN ET AL., PRISONER INTAKE SYSTEMS, supra note 22, at 10 (Exhibit 3. Major Components of the Intake Process: National Review Results) (reporting survey results showing that a mental health screen within 24 hours of an inmate's admission is mandatory in $74 \%$ of state intake facilities, and that $98 \%$ of all state correctional facilities conduct such screenings within this time frame); see also BECK \& MARUSCHAK, supra note 21, at 2 (documenting that $95 \%$ of state prison systems reported "that they either screened inmates or conducted psychiatric evaluations to determine inmate mental health or emotional status”). The Bureau of Justice Statistics found that maximum and medium security facilities were more likely than minimum security facilities to screen inmates at intake and conduct psychiatric assessments. See id. at 2 (Table 2) (finding that minimum security facilities conducted psychiatric assessments $62 \%$ of the time, compared to $84 \%$ at medium security facilities, and $88 \%$ at maximum security facilities).

${ }^{42}$ Coleman v. Wilson, 912 F. Supp. 1282, 1306 (E.D. Cal. 1995).

${ }^{43} \mathrm{Id}$.

${ }^{44}$ See id. at 1323-24. 
*DRAFT: PLEASE DO NOT CITE WITHOUT PERMISSION

MAY 3, 2013

adequately identify and treat the health care problems of new prisoners." 45 The court found that intake evaluators typically administered health screens in less than half the amount of time deemed adequate (seven minutes, instead of fifteen). ${ }^{46}$ Perhaps more egregious, screeners sometimes assessed inmates in groups, without regard to confidentiality or inmates' unwillingness to share sensitive information in this setting. ${ }^{47}$

Second, the quality of screening instruments varies among facilities, ${ }^{48}$ which can result in a low detection rate of inmates with serious mental illnesses. ${ }^{49}$ Federal reports warn that prison facilities may utilize tests that are not comprehensive, have not been verified, and have not been tested on representative prisoner populations. ${ }^{50}$ A 2007 report by the U.S. Department of Justice's National Institute of Justice observed that "screening procedures are highly variable[:] they may consist of anything from one or two questions about previous treatment to a detailed, structured mental status examination." 51 Studies show that the brief screening tests developed specifically for correctional settings fail to detect one out of every four offenders with a previous undetected mental disorder. $^{52}$ The use of other tests may yield less impressive results, with tragic

45 Plata v. Schwarzenegger, No. C01-01351, 2005 WL 2932253 at *12 (N.D. Cal. Oct. 3, 2005). For an analysis of this case and deficiencies in California prisons' assessment processes, see Ball, supra note 39, at 7-9.

${ }^{46}$ Plata, $2005 \mathrm{WL}$ at $* 12$. This case assessed the constitutional sufficiency of all health screens conducted at California prisons, not just those assessments pertaining to mental health.

${ }^{47}$ Id. at $* 13$.

48 See THIGPEN ET AL., supra note 1, at 14 ("Most prison authorities acknowledge the wisdom and legal necessity of screening and assessing inmates for mental health disorders. Determining how to screen and the methods to use remains challenging.”).

49 See infra notes 52-54; cf. HUMAN RIGHTS WATCH, supra note 33, at 101 ("If the screening questionnaire is adequate and properly administered, such personnel will probably have a fairly good rate of referring intake prisoners for more in-depth evaluations.”). I would submit that a "fairly good rate" of detection is not adequate when prisons do not offer a second routine screening and the consequences of failing to detect mental disorder within a prison environment are so dire.

${ }^{50}$ HARDYMAn ET AL., PRISONER INTAKE SyStems, supra note 22, at 14 ("Many states have validated their custody assessment instruments for their inmate populations. However, risk and needs assessment processes in some states lack such verification. They are not comprehensive nor have they been tested on prisoner populations typical of the agency. These assessments need to be expanded and validated to confirm their appropriateness for systematically evaluating both male and female prisoners.”).

51 Julian FORD ET AL., Mental HeAlth ScREens FOR CORRECTIONS 1-2 (Nat'l Institute of Justice 2007), http://www.nij.gov/pubs-sum/216152.htm.

52 Temporini, supra note 21, at 132 (citing studies showing that the Correctional Mental Health Screen and the Brief Jail Mental Health Screen are around 75\% effective at accurately detecting individuals with previously undetected mental disorder). During these tests, a correctional officer will look for current signs of mental illness and ask eight to twelve questions 
*DRAFT: PLEASE DO NOT CITE WITHOUT PERMISSION

MAY 3, 2013

consequences. In one study involving jail inmates, for instance, "fully $63 \%$ of inmates who were found to have acute mental symptoms through independently administered testing were missed by routine screening performed by jail staff" and remained untreated. ${ }^{53}$ Among state prisoners, a 2006 Bureau of Justice Statistics report found that $66 \%$ of state prisoners and $76 \%$ of federal prisoners with mental health problems had not received any form of mental health treatment since admission to prison, presumably at least partially a result of failures in detection through screening. ${ }^{54}$

Third, limitations inherent in the assessment process inhibit evaluators' ability to detect accurately inmates with mental health needs. Most fundamentally, initial mental health assessments may rely almost exclusively on information communicated by the inmate to the evaluating professional, either verbally or through his behavior. ${ }^{55}$ Inmates with serious mental disorders may decide not to-or may be unable to-communicate accurate information about their mental health history or status. Many inmates are aware that individuals who manifest bizarre thoughts or behavior may face adverse consequences, such as being placed on suicide watch, sent to administrative lockdown, forcibly administered medication, or preyed upon by other inmates. ${ }^{56}$ In addition, an inmate's mental

concerning symptomatology and prior mental health treatment. See id. at 130-35 (describing the booking mental health screen and including questions included in common correctional tests); see also AMERICAN PSYCHIATRIC AsSOCIATION, supra note 29, at 40-41 (describing the screening's components and objectives).

53 JULIAN FORD ET AL., supra note 51, at 2 (discussing Linda A. Teplin, Detecting Disorder: The Treatment of Mental Illness Among Jail Detainees, 58 J. OF Consulting AND ClinICAL PsyChOLOGY 233 (1990)); see also Robert L. Trestman, et al., Current and Lifetime Psychiatric Illness Among Inmates Not Identified as Acutely Mentally Ill at Intake in Connecticut's Jails, 35 J. AM ACAD. PSYCHIATRY LAW 490, 495-46 (2007) ("In general, the number of inmates with current and lifetime psychiatric illness who were not identified as acutely mentally ill at jail intake was high . . . . More than two of three inmates met the criteria for at least one lifetime psychiatric disorder, almost half for an anxiety disorder, and more than one-third for an affective disorder, substantially higher levels than those reported in community prevalence studies.”).

${ }^{54}$ See JAMES \& GLAZE, supra note 1, at 9 (reporting that, while "[a]ll Federal prisons and most State prisons . . . , as a matter of policy, provide mental health services to inmates, including screening inmates at intake for mental health problems, providing therapy or counseling by trained mental health professionals, and distributing psychotropic medication," only 34\% of state prisoners and $24 \%$ of federal prisoners who had a mental health problem received mental health treatment after admission).

${ }^{55}$ See Ball, supra note 39, at 8 (observing that mental health screens in California prisons "fail to incorporate objective factors alongside self-reporting; since inmates with acute mental illness are often unable to communicate their symptoms or diagnoses, self-reporting alone cannot adequately determine which prisoners are mentally ill”).

56 THIGPEN ET AL., supra note 1, at 14-15 (“An inmate's outward expression of bizarre thoughts or behavior or any loss of control may result in being put on suicide watch, being given medication, or being sent to administrative lockdown. In addition, prison inmates often exploit and 
*DRAFT: PLEASE DO NOT CITE WITHOUT PERMISSION

MAY 3, 2013

illness, low intelligence, mental retardation, or lack of verbal skills may hinder his ability to communicate his symptoms effectively. ${ }^{57}$ Moreover, inmates may be without psychiatric medication necessary to enable ordered thought or effective communication so may be unable to remember or communicate relevant information. Experts have warned that, when an inmate cannot adequately convey his thoughts or feelings, evaluators may misinterpret his difficulty as intentional malingering or an attempt to be manipulative. ${ }^{58}$ Also, anosognosia, or refusal to acknowledge one's disorder, ${ }^{59}$ is a common symptom of some serious mental illnesses, ${ }^{60}$ and inmates may go to great lengths to hide their illnesses as a manifestation of their disorders. ${ }^{61}$ Finally, co-occurring substance abuse disorders, head injuries, and developmental disorders can complicate diagnoses and treatment. ${ }^{62}$

In this setting, accurate detection of mental disorder may depend upon an evaluator's level of training. However, mental health professionals with extensive training in assessment and diagnosis, such as psychologists and psychiatrists,

take advantage of other inmates' weaknesses. As a result, inmates may fail to report their symptoms, and considerable time may pass before an inmate's mental illness is discovered and diagnosed.”).

57 See Ball, supra note 39, at 8; THIGPEN ET AL., supra note 1, at 15.

58 THIGPEN ET AL., supra note 1, at 15 ("Prison staff must exercise great caution in interpreting what is malingering or manipulative behavior. . . . An inmate's inability to think abstractly and lack of verbal skills may inhibit his or her ability to put common symptoms and feelings into words that adequately convey a sense of what is happening. Such inmates may be thought to be malingering when they cannot explain what they are feeling.”).

${ }^{59}$ Vesna Mildner, The Cognitive Neuroscience OF Human COMmuniCATiOn 253 (2008) (defining anosognosia as "[i]nability or refusal to acknowledge suffering from an illness or disorder").

${ }^{60}$ Brendan McLean, The Difficulty in Seeing Your Own Illness, NATIONAL AlLiAnCE ON MENTAL ILLNESS E-ADVOCATE (March 2011), http://www.nami.org/ADVTemplate.cfm?Section=20111\&Template=/ContentManagement/Conte ntDisplay.cfm\&ContentID=118505 (“Anosognosia can occur in any mental illness, regardless of its severity, although, it is more common to occur in cases of serious mental illness. It is more commonly found in schizophrenia, where approximately $60 \%$ of individuals diagnosed do not believe they have a mental illness, than in bipolar disorder or major depressive disorder.”); E.

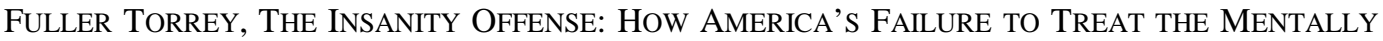
ILL ENDANGERS ITS CITIZENS 112 (2012) (noting that "approximately half of all individuals with schizophrenia and bipolar disorder are aware of their illness. The other half, however, have impaired awareness of their illness.”).

${ }^{61}$ Anosognosia Keeps Patients From Realizing They're Ill, PsyCHIATRIC NEWS, Sept. 7, 2001, at 12-32, available at http://journals.psychiatryonline.org/newsarticle.aspx?articleid=103404 (noting that "[p]eople will come up with "illogical and even bizarre explanations for symptoms and life circumstances stemming from their illness . . . along with a compulsion to prove to others that they are not ill”); THIGPEN ET AL., supra note 1, at 5 (noting "many adults with serious mental illness go to great lengths to hide their illness from staff or other inmates”).

${ }^{62}$ See THIGPEN ET AL., supra note 1, at 5. 
*DRAFT: PLEASE DO NOT CITE WITHOUT PERMISSION

MAY 3, 2013

rarely conduct mental health screenings. Instead, the screens are often performed more cheaply — and perhaps less effectively ${ }^{63}$ — by nurses, counselors, or social workers. ${ }^{64}$ Some institutions even rely upon correctional staff to perform mental health screens. ${ }^{65}$ According to a 2004 report by the National Institute of Corrections,

Mental health professionals who want to work in prisons are in short supply and are generally used to provide treatment, consultation, and training rather than screening. The result is that prison staff, sometimes with limited training, must distinguish on a daily basis inmates who are experiencing symptoms of a serious mental illness from those who are malingering or experiencing adjustment disorders. ${ }^{66}$

While correctional staff may feel confident in their abilities to detect overtly psychotic symptoms such as auditory or visual hallucinations, clear delusions, or incoherent speech, they "are considerably more uncertain about identifying less obvious-although equally serious - signs and symptoms of anxiety and depression.” ${ }^{67}$ It is also possible that correctional officials' tendencies to misread symptomatic behavior as willful and manipulative could shade their assessments. $^{68}$

Finally, intake evaluators often lack access to existing records or reports that could provide a more accurate picture of an inmate's mental health status. Evaluators often do not have the results of prior psychiatric evaluations, even those conducted in connection with a competency examination, insanity proceeding, or pre-trial detention. ${ }^{69}$ An inmate usually does not bring medication

63 Madrid v. Gomez, 889 F. Supp. 1146, 1219 (N.D. Cal. 1995) (“The [medical technical assistants] who briefly screen incoming inmates typically do not have the necessary training and background to recognize psychiatric illnesses.”).

${ }^{64}$ NATIONAL INSTITUTE OF CORRECTIONS, supra note 21, at 3 ("In many agencies and institutions, intake screening is a multi-stage process in which the initial screening is done by nonpsychologists, including nurses, counselors, physicians, or social workers.”).

65 See infra note 66; BECK \& MARUSCHAK, supra note 21, at 1 (finding, from the 2000 census of state adult correctional facilities, that $78 \%$ of state confinement facilities screened at intake, and 79\% of state correctional facilities conducted psychiatric assessments).

66 THIGPEN ET AL., supra note 1, at 14.

${ }^{67}$ JULIAN FORD ET AL., supra note 51, at 4.

${ }^{68}$ See supra note 39.

${ }^{69}$ HUMAN RIGHTS WATCH, supra note 33, at 101 ("Unfortunately, staff conducting the initial screening as well as more comprehensive examinations usually do not possess the results of prior psychiatric assessments, even assessments made during the prisoner's pre-trial incarceration or psychiatric diagnoses undertaken as part of trial competency or insanity defense proceedings. Such prior psychiatric workups may, indeed, never make it to the prison.”). 
*DRAFT: PLEASE DO NOT CITE WITHOUT PERMISSION

MAY 3, 2013

containers or a copy of his medical records or prescriptions to the diagnostic center. $^{70}$ In addition, mental health screens are often uninformed by jail evaluation and treatment records, even though state law may require that these records accompany an inmate upon transfer. ${ }^{71}$ An evaluator may even complete an offender's initial assessment and classification without the benefit of the court's presentence report. ${ }^{72}$ Without such data, screeners must rely on inmates' willingness and ability to share information about past and current mental health symptoms and treatment. As a result, inmates' mental disorders can go undetected.

Even when inmates' disorders are detected, however, prisons often fail to provide the treatment and protective environment necessary to prevent prisoners with serious mental disorders from experiencing serious harm in prison.

\section{Treatment, Housing, and Vulnerability}

In 1976, the U.S. Supreme Court held in Estelle v. Gamble that prisoners have an Eighth Amendment right to reasonably adequate medical care. $^{73}$ Although the Supreme Court has never addressed the issue, circuit courts of appeals have extended this principle to psychiatric and psychological care. ${ }^{74}$ In

70 See Ball, supra note 39, at 7 ("Diagnoses, prescriptions, and medications often fail to accompany prisoners at intake.”); Temporini, supra note 21, at 133-34 (noting the "more common" inmate who reports taking psychiatric medication but lacks documentation to this effect).

${ }^{71}$ See Ball, supra note 39, at 7 ("County jails are required by California law to evaluate mental health of prisoners, but very few of these records are transferred from jails to state prison system, forcing prison reception centers to administer redundant tests.”); see also HUMAN RIGHTS WATCH, supra note 33, at 1 ("If they are identified after screening and placed on mental health caseloads, prison data management systems often are inadequate to track services provided, or to ensure that the prisoners' records follow them when they are transferred to different prisons.”).

72 HARDYMAN ET AL., PRISONER INTAKE SySTEMS, supra note 22, at 13 ("Information typically contained in a presentence investigation report is critical to conducting a comprehensive and complete initial assessment. . . . Ideally, this information arrives at the intake facility with the prisoner or shortly thereafter. Many states reported, however, that these data are not received in a timely manner and sometimes arrive after the prisoner has been transferred from the intake facility to another prison.”).

73 See Estelle v. Gamble, 429 U.S. 97, 103-04 (1976) (“[D]eliberate indifference to serious medical needs of prisoners constitutes the 'unnecessary and wanton infliction of pain,' proscribed by the Eighth Amendment.” (internal citation omitted)); see also DeShaney v. Winnebago Dep’t of Social Services, 489 U.S. 189, 199-200 (1989) ("[W]hen the State by the affirmative exercise of its power so restrains an individual's liberty that it renders him unable to care for himself, and at the same time fails to provide for his basic human needs-e.g., food, clothing, shelter, medical care, and reasonable safety - it transgresses the substantive limits on state action set by the Eighth Amendment and the Due Process Clause.”).

${ }^{74}$ See Bowring v. Godwin, 551 F.2d 44, 47-48 (4th Cir. 1977) (holding that an inmate is "entitled to psychological or psychiatric treatment if a physician or other health care provider, 
*DRAFT: PLEASE DO NOT CITE WITHOUT PERMISSION

MAY 3, 2013

Ruiz v. Estelle, the District Court of Texas outlined a set of six guidelines that correctional institutions must meet to satisfy the Eighth Amendment. ${ }^{75}$ These minimum requirements include a systematic screening and evaluation program to identify inmates who require mental health treatment, treatment beyond segregation or close supervision, the employment of a sufficient number of trained mental health professionals to provide individualized treatment, accurate and confidential record-keeping, proper administration of medications, and identification and treatment of inmates at risk of suicide. ${ }^{76}$ Multiple courts and organizations have embraced the Ruiz criteria as the standard for constitutionally adequate mental health care in correctional settings. ${ }^{77}$

Prisons generally apply the principle of least eligibility, deliberately maintaining the level of health care a step below the services provided by the government outside of prison. ${ }^{78}$ Under this principle, "the level of prison conditions should always compare unfavorably to the material living standards of the laboring poor," 79 because prisoners "are the least eligible or least deserving members of society for any free benefit from the government," 80 including mental health care. Given its cost, older psychiatric medications-often with a greater host of side effects and lower rates of medication compliance than newer

exercising ordinary skill and care at the time of observation, concludes with reasonable medical certainty (1) that the prisoner's symptoms evidence a serious disease or injury; (2) that such disease or injury is curable or may be substantially alleviated; and (3) that the potential for harm to the prisoner by reason of delay or the denial of care would be substantial.”).

75 See Ruiz v. Estelle, 503 F. Supp. 1265, 1339 (S.D. Tex. 1980).

${ }^{76}$ Id. at 1339. The court also held, in reference to inmates with mental retardation, that " $\mathrm{t}$ ] hose whose needs are more specialized or complex than average inmates may not be denied their eighth amendment rights to adequate living conditions, protections from physical harm, and medical treatment by being forced to fit into a mold constructed for persons of average intelligence and physical mobility.” Id. at 1345. In this way, the court recognized a duty to provide disabled inmates with accommodations to ensure that their conditions of incarceration match as closely as possible those afforded to non-disabled inmates. T. Howard Stone, Therapeutic Implications of Incarceration for Persons with Severe Mental Illness, 24 AM. J. CRIM. L. 283, 325 (1997).

${ }^{77}$ See Fred Cohen, Legal Issues and the Mentally Disordered Inmate, in NATIONAL INSTITUTE of Corrections, Source BoOK on the Mentally Disordered Prisoner 32, 48 (1985); Kim P. Turner, Raising the Bars: A Comparative Look at Treatment Standards for Mentally Ill Prisoners in the United States, United Kingdom, and Australia, 16 CARDOZO J. INT'L \& COMP. L. 409, 424 \& n. 66 (2008).

${ }^{78}$ Frank Schmalleger \& John Ortiz SMyKLA, CORRECTIONS IN THE $21^{\text {st }}$ CentURy 205 (2001).

79 Richard Sparks, Penal “Austerity:” The Doctrine of Less Eligibility Reborn?, in PRISONS 2000 74, 74 (R. Matthews \& P. Francis, eds. 1996).

${ }^{80}$ Brandon K. Applegate, Penal Austerity: Perceived Utility, Desert, and Public Attitudes Toward Prison Amenities, 25 AM. J. CRIM. JusT. 253, 256 (2001). 
*DRAFT: PLEASE DO NOT CITE WITHOUT PERMISSION

MAY 3, 2013

medications - are the treatment modality of choice inside prisons. ${ }^{81}$ In addition, while the vast majority of prisons report providing some form of psychotherapy or counseling, ${ }^{82}$ prisons must restrict their distribution of this expensive service, ${ }^{83}$ and many inmates do not receive the therapy that they need to cope effectively within the prison environment. ${ }^{84}$

The default rule followed by many state correctional agencies, as well as the federal Bureau of Prisons, is to house inmates with major mental disorders with the general prison population at the appropriate security level. ${ }^{85}$ Inspired by the ideals epitomized in the Community Mental Health Centers Act $^{86}$ and Americans with Disabilities Act, ${ }^{87}$ these jurisdictions have adopted a philosophy of "mainstreaming" inmates with serious mental illnesses. ${ }^{88}$ Theoretically, this

${ }^{81}$ See HUMAN RIGHTS WATCH, supra note 33, at 115-17 (detailing the limited access to newer medications within some prison systems); id. at 121-25 (examining the side effects of older antipsychotic medications and some prisons' failure to monitor side effects appropriately); Adams \& Ferrandino, supra note 1, at 922; see also NATIONAL InSTITUTE OF CORRECTIONS, supra note 21, at 4 (reporting that all 49 departments of corrections responding to the survey indicated treating mentally ill inmates with psychotropic medication).

${ }^{82}$ See BecK \& MARUSCHAK, supra note 21, at 2 (Table 1) (reporting that $84 \%$ of state adult confinement facilities provide therapy).

${ }^{83}$ See NATIONAL InSTITUTE OF CORRECTIONS, supra note 21, at 4-5 (reporting that 14 departments of corrections (DOCs) typically provide inmates with non-acute mental illnesses with less than 1 hour per week of counseling, 10 DOCs typically provide these inmates 1 hour of counseling per week, 4 DOCs provide more than 1 hour of counseling per week, and 9 DOCs indicated that provision of therapy varies by need).

${ }^{84}$ HUMAN RighTS WATCH, supra note 33, at 109-114 (detailing the limited provision of therapeutic interventions in many prison systems); MacKain \& Messer, infra note 120, at 89 (observing that "few inmates receive care beyond the prescriptions of medication or assignments to separate housing").

${ }^{85}$ See BeCK \& MARUSCHAK, supra note 21, at 1, 4; HuMAN Rights WATCH, supra note 33, at 128. For instance, approximately $80 \%$ of prisoners with a mental disorder live in the general population in Ohio. HuMAN RIGHTS WATCH, supra note 33, at 128. Correctional officials designate these inmates as "special management" and may distinguish them through distinct outfits. Ira J. Silverman \& MANuel Vega, Corrections: A Comprehensive VieW 230 (1996).

${ }^{86}$ Community Mental Health Centers Act, 42 U.S.C. § 2689 et seq. (1963).

${ }^{87}$ See Americans with Disabilities Act, 42 U.S.C. §§ 12101-12213 (2012).

${ }^{88}$ See Fellner, Corrections Quandary, supra note 39, at 394 ("Apart from the mental health services that may or may not be provided, prisons typically treat prisoners with mental illness identically to all other inmates. There are no special allowances. Officials confine them in the same facilities, expect them to follow the same routines, and require them to comply with the same rules.”); Fed. Bureau of Prisons, P.S. 5310.13, Institution Management of Mentally Ill Inmates § 6, at 3 (U.S. Dep't of Justice 1995), available at http://www.bop.gov/policy/progstat/5310_013.pdf ("To ensure consistent treatment throughout the system, each institution shall develop a comprehensive approach for managing mentally ill inmates which emphasizes the management of 
*DRAFT: PLEASE DO NOT CITE WITHOUT PERMISSION

MAY 3, 2013

housing arrangement could facilitate equality of opportunity, full participation in programs, and independent living for disordered individuals. ${ }^{89}$ Since the "mainstream" prison environment is antitherapeutic, however, this approach has received its share of criticism. ${ }^{90}$

Confinement with the general prison population can be seriously damaging for an individual with a major mental disorder. ${ }^{91}$ As a preliminary matter, this high-stress environment exacerbates the symptoms of many serious mental illnesses and can cause degeneration. ${ }^{92}$ Moreover, recent studies demonstrate that individuals with serious mental illnesses, unable sufficiently to assess danger and modify their behavior to ward off attacks, are more prone to physical and sexual victimization than non-disordered individuals. ${ }^{93}$ In addition, strict conformance with prison rules can be very difficult for individuals with

these cases in a regular correctional setting, rather than in a hospitalized setting, as the preferred treatment strategy whenever and wherever feasible.”) .

${ }^{89}$ See Judy Anderson, Special Needs Offenders, in PRISON AND JAIL ADMINISTRATION: Practice AND THEORY 219, 220 (Peter M. Carlson \& Judith Simon Garrett, eds., 1999) (discussing how mainstreaming disordered individuals assures the provision of services available to the general prison population).

${ }^{90}$ See, e.g., Correctional Association of New York, Mental Health in the House of CORRECTIONS $\quad 43 \quad$ (2004), http://www.correctionalassociation.org/wpcontent/uploads/2004/06/Mental-Health.pdf (identifying "the overarching problem with the provision of mental health care in New York State prisons [as] the attempt of [the Office of Mental Health] to superimpose the community mental health model on the correctional system" and arguing that this model is inapt because "in the correctional system . . . not only is outpatient care sorely lacking in 'the community' of the general prison population, the violence and chaos of prison life itself can destabilize even mentally balanced individuals"); Shelia M. B. Holton, Managing and Treating Mentally Disordered Offenders in Jails and Prisons, in CORRECTIONAL Mental Health HandBoOK 101, 109-10 (Thomas J. Fagan \& Robert K. Ax, eds. 2003) (arguing that mentally ill inmates in a mainstreamed environment are likely to isolate themselves through withdrawal and enter the cycle of segregation); $c$. HUMAN RigHTS WATCH, supra note 33, at 133 (discussing why deinstitutionalization and the community mental health model are problematic in the prison context).

${ }^{91}$ See Marshall T. Bewley \& Robert D. Morgan, A National Survey of Mental Health Services Available to Offenders with Mental Illness: Who is Doing What?, 35 LAW \& HuM. BEHAV. 351, 352 (2011) ("Simply stated, prison environments are not conducive to optimal mental health functioning."); Richard C. McCorkle, Gender, Psychopathology, and Institutional Behavior: A Comparison of Male and Female Mentally Ill Prison Inmates, 23 J. CRIM. Just. 53, 54 (1995) ("For those with predispositions, the incarceration experience can actually trigger psychopathology."); HUMAN RighTS WATCH, supra note 33, at 53 ("Mental health experts have described prisons as a 'toxic' environment for the seriously mentally ill.”).

${ }^{92}$ See, e.g., Holton, supra note 90, at 108-110; Jamie Fellner, A Conundrum for Corrections, A Tragedy for Prisoners: Prisons as Facilities for the Mentally Ill, 22 WASH. U. J.L. \& POL'Y 135, 140 (2006).

${ }^{93}$ See Johnston, Vulnerability, supra note 12, at 161-69 \& nn.64-83 (physical assault) \& 91103 (sexual assault). 
*DRAFT: PLEASE DO NOT CITE WITHOUT PERMISSION

MAY 3, 2013

cognitive and behavioral limitations, and studies confirm that prisoners with serious mental illnesses are more likely than non-disordered prisoners to violate prison rules. ${ }^{94}$ As a result, seriously ill prisoners are disproportionately punished in solitary confinement, ${ }^{95}$ where they are especially susceptible to decompensation, psychotic breaks, and suicide ideation. ${ }^{96}$ A 2004 report by a state correctional agency concedes that "finding safe, humane, and non-punitive methods for handling inmates who are experiencing the symptoms of mental illness is an ongoing challenge for prison administrators." 97

Identified as particularly vulnerable to attack, seriously disordered offenders may be housed in isolation as a means of protection. Through a process called external classification, correctional authorities, based largely on information collected at intake, determine a prisoner's custody level (minimum, medium, or maximum) and his facility placement. ${ }^{98}$ At a facility, correctional officials typically undertake the process of internal classification, which determines how an individual of a particular custody level should be housed and the programming and resources he requires. ${ }^{99}$ While aspects of inmate classification have become increasingly objectified over time, ${ }^{100}$ facilities have long based protective custody decisions on the subjective judgments of

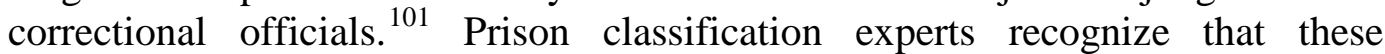

${ }^{94}$ See id. at 170-74 nn.114-34.

95 See id. at 174-76 \& nn.146-49. A 2004 report by the National Institute of Corrections documented that $47 \%$ of states reported subjecting mentally ill inmates who are disruptive to the same maximum-custody policies as non-disordered inmates. AUSTIN \& MCGINNIS, supra note 41, at 37.

${ }^{96}$ See Johnston, Vulnerability, supra note 12, at 176-78 \& nn.150-55.

97 Adams \& Ferrandino, supra note 1, at 914 (quoting Oregon Dept. of Corrections, Managing Mental Illness in Prisons Task Force: Findings and Recommendations 45 (2004)).

98 AUSTIN \& MCGINNIS, supra note 41, at 7.

99 See PATRICIA L. HARDYMAN, ET AL., INTERNAL PRISON ClASSIFICATION SySTEMS: CASE STUDIES IN THEIR DEVELOPMENT AND IMPLEMENTATION 1-2 (Department of Justice 2002).

100 See AUSTIN \& MCGINNIS, supra note 41, at 1 ("Although most prison systems have implemented objective classification systems that have proven effective in determining the custody level assigned to an inmate designated for the general population, less attention has been devoted to identifying inmates who should be placed in a special management category such as administrative segregation or protective custody.”).

${ }^{101}$ Id. at 7-8 ("Correctional administrators have long relied on professional clinical judgment in assessing prisoners for . . . placement in administrative segregation or protective custody. This method has been favored because it requires only a professional with the skill and experience necessary for the assessment. In general, no forms must be completed and no tests for reliability and validity are needed.”); NATIONAL RAPE ELIMINATION COMMITTEE REPORT, supra note 6, at 76 (observing that "many" facilities rely on subjective assessments of inmates' risk of sexual assault and do not conduct targeted risk assessments."); Ron Angelone, Protective Custody Inmates, in PRISON AND JAIL ADMINISTRATION supra note 89, at 226, 229-31 (observing that "some prison 
*DRAFT: PLEASE DO NOT CITE WITHOUT PERMISSION

MAY 3, 2013

subjective assessments may yield arbitrary determinations with tragic results. ${ }^{102}$ Ironically, those inmates fortunate enough to be removed from predators in the general population may be confronted with a different, but equally significant, danger when assigned to protective custody. In protective custody, inmates are often housed in highly restrictive conditions that resemble those in disciplinary isolation, ${ }^{103}$ with isolation for twenty-one to twenty-four hours per day. ${ }^{104}$

systems are examining internal institutional classification in order to address housing and security needs such as protective custody" but ultimately concluding that "sophisticated statistical prediction methods cannot be relied upon to ensure accurate identification of protective custody inmates” and endorsing a subjective, discretion-based system). Some prisons employ a formal internal classification process to govern interfacility decisions, but many do not. See HARDYMAN ET AL., PRISONER INTAKE SYSTEMS, supra note 22, at 11 ("Most states do not use a formal internal classification system that assigns prisoners to a housing unit, cell, program, or job.”).

102 See AUSTIN \& MCGINNIS, supra note 41, at 7-8 ("Unfortunately, professional judgment has been shown to be by far the least accurate risk assessment method. Too often, such judgments are no more than 'gut' reactions that may vary from expert to expert with regard to the same prisoner.” (internal citations omitted)); James Austin, External and Internal Classification, in

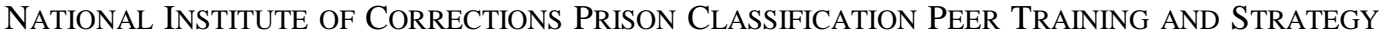
SESSION: WHAT'S HAPPENING WITH PRISON ClASSIFICATION SYSTEMS? SEPTEMBER 6 - 7, 2000 PRoceEdings 5, 7 (Feb. 15, 2001), http://nicic.gov/Library/016707 ("Currently, most prisons systems have less structured internal classification systems which can often result in serious incidents or high-profile escapes. Often, inmates are inappropriately housed, programmed or improperly separated.”). Under the recently issued rule implementing the Prison Rape Elimination Act, however, all inmates will need to be assessed, using an objective screening instrument, during an intake screening for their risk of being sexually victimized by other inmates. See National Standards to Prevent, Detect, and Respond to Prison Rape, § 115.4, Docket No. OAG-131 (signed May 16, 2012) (to be codified at 28 C.F.R. pt. 115), www.ojp.usdoj.gov/programs/pdfs/prea_final_rule.pdf. For a description of several actuarialbased risk assessment instruments, see AUsTIN \& MCGINNIS, supra note 41, at 15-23.

103 See Craig Haney, Mental Health Issues in Long-Term Solitary and 'Supermax' Confinement, 49 CRIME \& DELINQUENCY 124, 135 (2003) (“Conditions of confinement for protective custody prisoners are in many ways similar to those in supermax confinement. That is, they are typically segregated from the rest of the prison population, restricted or prohibited from participating in prison programs and activities, and often housed indefinitely under what amount to oppressive and isolated conditions.”); James E. Robertson, The Constitution in Protective Custody: An Analysis of the Rights of Protective Custody Inmates, 56 U. CIN. L. REV. 91,91 (1987) ("In exchange for security, protection inmates often experience conditions of confinement similar to those imposed as punishment for disciplinary infractions.”); see also HUMAN RIGHTS WATCH, No ESCAPE: MALE RAPE IN U.S. PRISONS 31 (2001) ("Prisons and jails typically have a protective custody classification for isolating and protecting prisoners believed likely to be victimized by others. Prisoners assigned to this status are usually housed in separate areas of the facility, in which conditions are often highly restrictive.”).

104 See Sharon Dolovich, Strategic Segregation in the Modern Prison, 48 AM. CRIM. L. REV. 1, 3-4 (2011) (stating that, due to the fact that gay men and trans women are "almost automatically" targets for sexual abuse, many carceral facilities routinely house these inmates in protective custody, "a classification that typically involves isolation in 'a tiny cell for twenty-one to twenty-four hours a day,' the loss of access to any kind of programming (school, drug, 
*DRAFT: PLEASE DO NOT CITE WITHOUT PERMISSION

MAY 3, 2013

Individuals with serious mental disorders often deteriorate in this restrictive environment. ${ }^{105}$

When a prisoner reaches a state of crisis or an acute state of mental illness, prison authorities typically remove the prisoner from segregation or the general population and transfer him to an acute crisis unit for inpatient mental health services. ${ }^{106}$ These units may reside within the prison, in a separate mental health facility, or in a public or private hospital. ${ }^{107}$ Stays in these units are temporary; the goal is to treat and stabilize the inmate for return to the general population or, perhaps, a residential treatment unit. ${ }^{108}$ Criteria for admission match those required for involuntary civil commitment, ${ }^{109}$ and treatment resembles that available in an inpatient psychiatric hospital, with significant psychotherapy and pharmaceutical regimens. ${ }^{110}$

In addition, some states house mentally ill inmates in separate units or facilities on a longer term basis, especially when inmates cannot function adequately or cope in the general population. ${ }^{111}$ The most comprehensive report

treatment, etc.), and even deprivation of basics like 'phone calls, showers, group religious worship, and visitation'” (internal citations omitted)); Robertson, supra note 103, at 122 (noting that inmates in protective custody spend twenty-two hours in isolation per day).

105 See supra note 96.

106 NATIONAL INSTITUTE OF CORRECTIONS, supra note 21, at 4-5 (identifying the following "main criteria used to determine when mentally ill inmates are housed outside the general population": when an inmate requires inpatient care (22 DOCs); when an inmate is in crisis or experience an acute state of mental illness (17 DOCs); when an inmate is severely impaired, decompensating, or is becoming increasingly psychotic (14 DOCs); and when officials deem an inmate to be dangerous or at risk of self-harm (11 DOCs and the Bureau of Prisons)); HUMAN Rights WATCH, supra note 33, at 128; CORRECTIONAL AsSOCIATION OF NEW YORK, supra note 90 , at 41 .

107 NATIONAL INSTITUTE OF CORRECTIONS, supra note 21, at 5.

108 HumAN Rights WATCH, supra note 33, at 128. For more information on residential treatment units, or intermediate care facilities, see infra Part VI.B.1.

109 See, e.g., Virginia Department of Corrections, Operating Procedure: Mental HEALTH SERVICES: LEVELS OF SERVICE 3 (2012), available at http://www.vadoc.state.va.us/about/procedures/documents/700/730-3.pdf (stating that an inmate may be committed to a crisis unit when "there exists a substantial likelihood that, as a result of the mental illness, the offender will, in the near future [harm himself or others, or] lack capacity to protect himself and provide for his basic needs”). In addition, less restrictive alternatives generally must be deemed unsuitable.

${ }^{110}$ HUMAN RigHTS WATCH, supra note 33, at 128.

111 See THIGPEN ET AL., supra note 1, at 8 ("Many prisons acknowledge the need for chronic care programs or special needs housing units within the correctional setting for inmates with chronic mental illness who do not require inpatient treatment but do require a therapeutic environment due to their inability to function adequately within the general population.”); HUMAN RighTS WATCH, supra note 33, at 128 ("Prison mental health services typically includes at least 
*DRAFT: PLEASE DO NOT CITE WITHOUT PERMISSION

MAY 3, 2013

on segregated housing to date, based on the 2000 Census of State and Federal Adult Correctional Facilities, disclosed the existence of 155 facilities, in 47 states, that provide mental health/psychiatric confinement as a special function. ${ }^{112}$ Facility administrators specified that mental health confinement was the primary function of twelve facilities and the secondary function of 143 facilities. ${ }^{113}$ While some states restrict their use of special facilities to short-term housing for inmates suffering from acute episodes, others report utilizing these facilities as long-term segregated housing for inmates with mental disorders. ${ }^{114}$

One increasingly popular option employed by correctional agencies involves the use of intermediate care facilities or residential treatment units, which are designed to assist mentally disordered inmates who are unable to function adequately in the general population. These units provide prisoners, who may stay in the units for varying amounts of time, ${ }^{115}$ with effective clinical care and the skills inmates need to cope effectively in the general prison population.

three general levels. . . . Sub-acute care is typically provided outside of hospital settings for prisoners suffering from severe and chronic conditions that require intensive case management, psychosocial interventions, crisis management, and psychopharmacology in a safe and contained environment.”); NATIONAL INSTITUTE OF CORRECTIONS, supra note 21, at 5-6 (reporting that 16 of 49 responding jurisdictions indicated that a "main" reason for deciding when to house an inmate with mental illness outside the general population included "when the inmate can't function adequately or cope in the general population," and that a smaller (unspecified) number of respondents indicated that separate housing would be appropriate "when the inmate needs structure; when the [General Assessment Functioning score] drops under 50; when the inmate needs help staying on medications; when the inmate becomes a management problem; when the inmate is unable to care for him or herself; when the inmate is vulnerable; and when the inmate needs more observation”).

112 BECK \& MARUSCHAK, supra note 21, at 2; see also NATIONAL INSTITUTE OF CORRECTIONS, supra note 21, at 6-7 (conveying that 33 states, the Bureau of Prisons, Puerto Rico, and Guam reported providing separate housing units for inmates with mental disorders in at least one institution, including five states that provided "sheltered," "supportive," "partial care,” or "assisted housing” for inmates with mental disorders; and eight DOCs reported providing specialized facilities for prisoners with mental illnesses, which "may be used for all mentally ill inmates or only those whose mental illness is most severe," depending on the agency). According to the report, North Dakota, Rhode Island, and Wyoming lacked a special psychiatric confinement facility and confined inmates needing segregation in state hospitals, prison infirmaries, or special needs units within general confinement facilities. BECK \& MARUSCHAK, supra note 21, at 2.

113 BECK \& MARUSCHAK, supra note 21, at 4.

${ }^{114}$ Id. ("In some States these facilities are used to house mentally ill inmates separately from the general population; in other States they are used to remove inmates in response to acute episodes for a short term.”); see also Holton, supra note 90, at 115-16 (describing short- and longterm options employed by correctional systems to accommodate inmates with mental illnesses).

\footnotetext{
${ }^{115}$ See infra note 257.
} 
*DRAFT: PLEASE DO NOT CITE WITHOUT PERMISSION

MAY 3, 2013

No recent report catalogues all the states that maintain intermediate care units, ${ }^{116}$ but research reveals the existence of units in New York, ${ }^{117}$ Washington, ${ }^{118}$ Ohio, ${ }^{119}$ North Carolina, ${ }^{120}$ Virginia, ${ }^{121}$ Kansas, ${ }^{122}$ New Mexico, ${ }^{123}$ Mississippi, ${ }^{124}$ Vermont, ${ }^{125}$ Alabama, ${ }^{126}$ California, ${ }^{127}$ and Wyoming. ${ }^{128}$ These units are associated with lower levels of mental disorder, disciplinary violations, and victimization, and may yield aggregate cost savings for prisons. ${ }^{129}$ Given the widely touted success of these units, other states may choose to emulate this option, to the extent they have not done so already. ${ }^{130}$ Intermediate care facilities are detailed in Part VI.B.1 below.

116 See supra note 111; see also NAT'L COMM’N ON CORR. HEALTH CARE, ThE HEALTH STATUS OF SOON-TO-BE-RELEASED INMATES: A REPORT TO CONGRESS, vol. I xii \& n.22 (2002), https://www.ncjrs.gov/pdffiles1/nij/grants/189735.pdf (reporting, based on a 1992 study, that only $36 \%$ of prisons have specialized housing for inmates with stable mental health conditions).

${ }^{117}$ CORRECTIONAL AsSOCIATION OF NEW YORK, supra note 90, at 35.

${ }^{118}$ Washington Department of Corrections, Mental Health Treatment Services: THERAPY AND MEDICINE OFFER NEW LIVES 3 (2008), http://www.doc.wa.gov/aboutdoc/docs/p351gmentalhealthtreatmentservicesfactsheet.pdf.

119 OHIO DEPARTMENT OF REHABILITATION AND CORRECTION, RESIDENTIAL TREATMENT $\begin{array}{llllll}\text { UNITS } & 2 & \text { (2010) } & \text { [hereinafter } & \text { OHIO }\end{array}$ http://www.drc.ohio.gov/web/drc_policies/documents/67-MNH-23.pdf (operating procedure).

${ }^{120}$ Sally J. MacKain \& Charles E. Messer, Ending the Inmate Shuffle: An Intermediate Care Program for Inmates with a Chronic Mental Illness, 4 J. OF FORENSIC PYSCHOL. PRACTICE 87, 9192 (2004).

${ }^{121}$ VIRGINIA DEPARTMENT OF CORRECTIONS, supra note 109, at 3, 5-6.

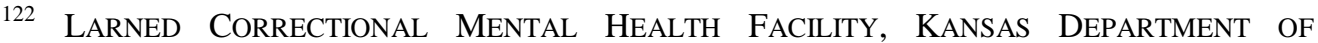
CORRECTIONS, http://www.doc.ks.gov/facilities/lcmhf (last visited Jan 26, 2013).

123 New Mexico Corrections Department, Mental Health Treatment Center: PSYCHIATRY, MEDICAL, AND NURSING CARE 2, 4-7 (2012), available at http://corrections.state.nm.us/policies/docs/CD-172300.pdf (operating procedure).

124 Terry A. Kupers et al., Beyond Supermax Administrative Segregation: Mississippi's Experience Rethinking Prison Classification and Creating Alternative Mental Health Programs, 36 CRIM. JUST. \& BEHAV. 1038 (2009).

125 Vermont DePARTMENT OF CORRECTIONS, RESIDENTIAL TREATMENT PROGRAMS 2 (1997), available at http://www.doc.state.vt.us/about/policies/rpd/correctional-services-301-550/361-370programs-treatment-programs/361.01.09\%20Residential\%20Tx\%20Programs.pdf.

126 Alabama Department of Corrections, Treatment Planning 4 (2010) (operating procedure).

${ }^{127}$ HUMAN RightS WATCH, supra note 33, at 131.

128 Wisconsin DepartMENT OF CORRECTIONS \& DEPARTMENT OF HEALTH SERViCEs, AN Evaluation: INMATE MENTAL HEAlth CARE 51-61 (2009), available at http://legis.wisconsin.gov/lab/reports/09-4full.pdf (Wisconsin Resource Center).

${ }^{129}$ See infra notes 259-268 and accompanying text.

130 See HuMAN Rights WATCH, supra note 33, at 130 (citing Dr. Jeffrey Metzner as stating that "Michigan, Ohio, Georgia, New York, Vermont, New Jersey, Puerto Rico, Colorado, and 
*DRAFT: PLEASE DO NOT CITE WITHOUT PERMISSION

MAY 3, 2013

In summary, although prisons have processes and resources in place to identify, treat, and protect offenders with serious mental illnesses, these mechanisms do not guarantee that a prison will recognize an individual's mental disorder or protect an individual in a given case. Mental health screenings have structural limitations that impede evaluators' abilities to detect accurately individuals with major mental disorders. Moreover, internal classification processes used to identify at-risk individuals often rely on subjective assessments of vulnerability, so may yield arbitrary results. Equally important, the only longterm housing options available to seriously disordered individuals in a given facility may include units in the general prison population, where disordered individuals face a heightened risk of predation and often cannot cope effectively with prison rules and stress, and isolation, which inmates with serious mental illnesses are unlikely to tolerate well. All too often, prisoners with serious mental disorders decompensate, are admitted to an inpatient facility until they stabilize, and then are returned to the original restrictive or dangerous environment, where the destructive cycle starts anew. ${ }^{131}$

Judges could serve an important function in helping to identify seriously disordered offenders at risk of serious harm in prison, and in crafting sentences to ensure their appropriate penal bite and humanity. Before detailing potential sentencing options, however, the next Part defends a central premise of this Article: offender vulnerability is an appropriate consideration for sentencing, and is not an issue that should be reserved for penal administrators.

\section{Legitimacy of Recognizing Vulnerability to Harm at Sentencing}

Allowing judges to modify a seriously disordered offender's sentence in light of his vulnerability to serious harm would allow judges better to fulfill their institutional function and achieve the aims of punishment. The sentencing judge is charged with selecting and conveying the type and length of sentence warranted by an offender's crime, within limits established by the legislative branch. ${ }^{132} \mathrm{~A}$ sanction that is appropriate for an offender without disability may be wholly

Kansas have all taken steps towards creating networks of sub-acute care facilities”). Correctional agencies do not employ consistent terminology for these units, so it can be difficult to discern the long- or short-term nature of mental health units included in government reports. See NATIONAL INSTITUTE OF CORRECTIONS, supra note 21, at 6 (listing ways in which mental health units may be characterized).

${ }^{131}$ See Fellner, Corrections Quandary, supra note 39, at 404; MacKain \& Messer, supra note 120, at 88 (describing this phenomenon).

132 The U.S. Constitution did not assign the sentencing power to one branch of government, and all three branches may properly play a role in sentencing. See Kieran Riley, Trial By Legislature: Why Statutory Mandatory Minimum Sentences Violate the Separation of Powers Doctrine, 19 B.U. PUB. INT. L. J. 285, 302 (2010); supra note 13. 
*DRAFT: PLEASE DO NOT CITE WITHOUT PERMISSION

MAY 3, 2013

excessive, criminogenic, or even inhumane for an offender lacking the cognitive or behavioral capabilities necessary to cope within a given punitive environment. Consideration of the aims of punishment allows the identification of possible theoretical justifications for considering an offender's vulnerability to harm at sentencing. Though additional justifications may exist, ${ }^{133}$ consideration of vulnerability to serious harm in prison may be critical to effectuating retributive or rehabilitative goals.

\section{A. Retributive Rationales}

Two retributive rationales support a judge's tailoring of an offender's sentence based on his likely hardship or injury in prison. The first justification, as I have argued at length elsewhere, derives from a just deserts theory of retributive punishment. ${ }^{134}$ Under a just deserts approach, the severity of an offender's punishment should reflect the offender's culpability and the harm that he effectuated through his criminal act. ${ }^{135}$ While most scholars measure a punishment's severity by reference to an objective standard, ${ }^{136}$ some commentators have recognized that sanctions such as incarceration have a foreseeable, disparate impact on vulnerable classes of offenders, such as the elderly, young, physically disabled, and mentally ill. ${ }^{137}$ In response, scholars including Professors Andrew Ashworth and Andrew von Hirsch have espoused a principle of equal impact, which dictates that, "when an offender suffers from

${ }^{133}$ A third potential justification, mercy, is not addressed in this Article.

134 See Johnston, Vulnerability, supra note 12, at 183-229.

135 See ANDREW VON HiRsch \& ANDREW ASHWORTH, Proportionate SENTENCING: EXPLORING THE PRINCIPLES 4 (2005) (explaining that the desert rationale of proportionalist sentencing underlying retributivism "rests on the idea that the penal sanction should fairly reflect the degree of reprehensibleness (that is, the harmfulness and culpability) of the actor's conduct”).

136 See, e.g., David Gray, Punishment as Suffering, 63 VANDERBILT L. ReV. 1619, 1658 \& n.195 (2010) ("Subjectivist critics' claims to the contrary notwithstanding, retributivism defines punishment as a restraint on liberty or other consequence that is determined and justified objectively by reference to a culpable offense.”).

137 See, e.g., VON HiRsch \& ASHWORTH, PROPORTIONATE SENTENCING, supra note 135, at 4243, 172-73, 176; Andrew Ashworth \& Elaine Player, Sentencing, Equal Treatment, and the Impact of Sanctions, in FundamentAls OF SENTENCING THEORY: ESSAYS IN HONOUR OF ANDREW VON HIRSCH 251, 259-60, 274-75 (Andrew Ashworth \& Martin Wasik eds., 1998); Andrew Ashworth, Sentencing Young Offenders, in PRINCIPLED SENTENCING 294, 300 (Andrew von Hirsch et al. eds., 3d ed. 2009) (asserting that "we should recognise that punishments are generally more onerous for the young because they impinge on important developmental interests, in terms of education and socialisation, for which the teenage years are a crucial phase" and that "[p]roportionality theory thus requires that sentence levels be significantly lower than those for adults . ...”); Barry C. Feld, A Century of Juvenile Justice: A Work in Progress or a Revolution that Failed?, 34 N. KY. L. REV. 189, 247-48 (2007); see also JEREMY BENTHAM, PRINCIPLES OF MORALS AND LEGISLATION, Ch. VI, para. 6 (1789) (delineating “circumstances influencing sensibility”). 
*DRAFT: PLEASE DO NOT CITE WITHOUT PERMISSION

MAY 3, 2013

certain handicaps that would make his punishment significantly more onerous, the sanction should be adjusted in order to avoid its having an undue differential impact on him.”138 The equal impact principle thus acknowledges the foreseeable, typical, and serious side-effects that certain penalties hold for vulnerable populations and seeks to adjust ordered sanctions so that members of vulnerable classes receive penalties of roughly equivalent severity as non-vulnerable individuals. ${ }^{139}$ Understood properly, the equal impact principle does not call for a reduction in punishment, but rather for equalizing the severity of penalties imposed on equally blameworthy offenders. ${ }^{140}$ In this way, recognition of the equal impact principle may be necessary, at least in extreme cases, for the effectuation of proportionality. ${ }^{141}$

138 VON HiRSCH \& AshWORTh, PROPORTIONATE SENTENCING, supra note 135, at 172; see also Ashworth \& Player, supra note 137, at 253 (advocating “a general principle of equal treatment, by which we mean that a sentencing system should strive to avoid its punishments having an unequal impact on different offenders or groups of offenders"). The roots of the equal impact theory can be traced to Jeremy Bentham. See BENTHAm, supra note 137, Ch. XIV, para. 14 (articulating a principle of equal impact).

139 See von Hirsch \& Ashworth, Proportionate Sentencing, supra note 135, at 172; id. at 176 (explaining that the aim of the equal impact principle, when applied in the case of an offender with a physical handicap, is to make "adjustments in sentence to deal with certain foreseeable differential impacts”); ANDREW AsHwORTH, SENTENCING AND PENAL POLICY 277 (1983) ("The argument, then, is that whilst it is just to impose the same sentence on two equally culpable offenders for two equally grave offences, it is unjust to do so if the two offenders have such differing 'sensibilities' that the sentence would have a significantly different effect on each of them. The sentencer should take account of any relevant and significant differences, and should strive to achieve equality of impact.”); see also Adam J. Kolber, The Subjective Experience of Punishment, 109 ColuM. L. REV. 182, 199-210 (2009) (arguing that various versions of retributivism must factor subjective experience into sentencing in order to fulfill the proportionality requirement); Johnston, Vulnerability, supra note 12, at 194-95 nn.219-23, 221-29.

This stance may depend upon subscription to a definition of punishment that includes foreseeable, substantial risks of serious harm, proximately caused by the state during confinement. See Johnston, Vulnerability, supra note 12, at 186-87. Traditionally, scholars have defined punishment as including only hardships or deprivations intended and authorized by a legitimate sentencing authority. See, e.g., Hugo Adam Bedau, Feinberg's Liberal Theory of Punishment, 5 BuFF. CRIM. L. REV. 103, 111-12 (2001) (observing that the definitions of punishment offered by Joel Feinberg, Stanley Benn, Antony Flew, H.L.A. Hart and John Rawls all specify that deprivations or suffering imposed on a person for a legal wrong must be "intended" by a recognized legal authority); see also Johnston, Vulnerability, supra note 12, at 188 n.198 (collecting sources).

140 See von Hirsch \& Ashworth, Proportionate Sentencing, supra note 135, at 173 ("The equal-impact principle does not actually function as true equity mitigation, because it actually does not call for qualifying defendants to suffer less punishment: it merely is a way of avoiding that such defendant be made to suffer more.”).

141 See Ashworth \& Player, supra note 137, at 255 (arguing that "those theories which have some requirement of proportionality of sentence to the seriousness of the offence must surely 
*DRAFT: PLEASE DO NOT CITE WITHOUT PERMISSION

MAY 3, 2013

Second, a retributive understanding of punishment suggests that a sentencing system should consider an offender's vulnerability in order to avoid imposing inhumane punishments. Retributivism, premised upon respect for the moral dignity and personhood of the offender, ${ }^{142}$ cannot tolerate punishments that violate human dignity, ${ }^{143}$ fail to recognize the personality of offenders, ${ }^{144}$ or "approximate a system of sheer terror in which human beings are treated as animals to be intimated and prodded." ${ }^{\prime 45}$ When, exactly, a mode of punishment or conditions associated with a particular sanction cross the line from harsh to inhumane is a difficult contextual question that ultimately reflects the sensitivities and values of a particular society. ${ }^{146}$ While corporal punishment was once

concern themselves with this problem [of equal impact]"); cf. VON HIRSCH \& ASHWORTH, PROPORTIONATE SENTENCING, supra note 135, at 172 (asserting that, although the "'equal impact' principle is connected with the proportionalist sentencing model, [it] is not part of it in standard cases" and that its use should be reserved for "unusual cases that diverge significantly from the norm").

${ }^{142}$ See, e.g., BARBARA A. HUDSON, UnderstANDING Justice 51 (2003) (discussing the moral theory of Immanuel Kant and characterizing it as resting "on a model of the human as someone whose actions are the result of moral choices"); Jeffrie G. Murphy, Marxism and Retribution, 2 PHIL. \& PUB. AfFAIRS 217 (1973) (outlining Immanuel Kant's theory of punishment with an emphasis on its manifestation of respect for dignity, autonomy, rationality, and rights).

143 See JefFrie G. Murphy, Retribution, Justice, AND Therapy 233 (1979) ("A punishment will be unjust (and thus banned on principle) if it is of such a nature as to be degrading or dehumanizing (inconsistent with human dignity). The values of justice, rights and desert make sense, after all, only on the assumption that we are dealing with creatures who are autonomous, responsible, and deserving of the special kind of treatment due that status.").

${ }^{144}$ See id. at 233 (decrying "a punishment which is in itself degrading, which treats the prisoner as an animal instead of a human being, which perhaps even is an attempt to reduce him to an animal or a mere thing” as inconsistent with human dignity).

${ }^{145}$ Herbert Morris, Persons and Punishment, 52 MonIST 475, 488 (1968).

${ }^{146}$ See, e.g., JOHN KLEINIG, PUNISHMENT AND DESERT 123 (1973) (“[T]here is a limit to the severity of the punishment which can be humanely inflicted upon a wrongdoer. What these limits are is of course a matter for debate, to be decided partly by recourse to normative considerations.”); David Garland, Perspectives on Punishment, 14 CRIME \& JUST. 115, 143 (1991) ("[P]unishments are, in part, determined by the specific structure of our sensibilities, and . . . these sensibilities are themselves subject to change and development.”).

This moral question parallels the legal inquiry of when punishment is deemed cruel and unusual under the Eighth Amendment. In Farmer v. Brennan, the U.S. Supreme Court held that, for an inmate's confinement to violate the Eighth Amendment, conditions must pose "a substantial risk of serious harm.” 511 U.S. 825, 834 (1994). In addition to proving that conditions pose a substantial risk of harm, the inmate must demonstrate that the responsible prison official acted with "deliberate indifference" towards his health or safety in allowing these conditions to exist. Farmer, 511 U.S. at 834. Deliberate indifference requires that prison officials have actual knowledge that an inmate faces a substantial risk of serious harm and fail to take reasonable measures to abate the risk. See Farmer, 511 U.S. at 838-42. Arguably, retributive theory, with its focus on justice, morality, the dignity of the offender, and proportionate punishment, can and 
*DRAFT: PLEASE DO NOT CITE WITHOUT PERMISSION

MAY 3, 2013

commonplace, much of the civilized world now rejects corporal sanctions, such as whipping and lashing, as inhumane. ${ }^{147}$ The same would hold true for sanctions intended to disrupt profoundly one's personality or senses or to precipitate mental breakdown. ${ }^{148}$ Philosophers, legal scholars, and courts have distinguished incarceration from corporal sanctions, however, by emphasizing its primary function as a deprivation of rights. ${ }^{149}$ When incarceration carries a high likelihood of victimization and psychological harm for individuals with certain vulnerabilities, however, incarceration may more closely resemble an inhumane corporal penalty than an unobjectionable deprivation of rights. ${ }^{150}$ If this is true,

should be more sensitive to risk of physical and psychological harm than current Eighth Amendment jurisprudence. See Johnston, Vulnerability, supra note 12, at 213 n.314.

147 See, e.g., Garland, supra note 146, at 143 (identifying "a whole range of possible punishments (tortures, maimings, stonings, public whippings, etc.) that are simply ruled out as 'unthinkable' because they strike us as impossibly cruel and 'barbaric'-as wholly out of keeping with the sensibilities of modern, civilized human beings"); Ruplekha Khullar, Punishment and Human Rights, in ApPlied ETHICS AND Human Rights: CONCEPTUAL ANALYsis AND CONTEXTUAl Applications 183, 187 (Shaski Motilal ed., 2010) ("The horror of retributive measures has, however, propelled humanity to move away from corporal punishment towards more subtle methods.”); ANDREW VON HIRSCH, DOING JUSTICE 111 n.* (1976) (rejecting corporal punishment as a permissible form of punishment because it "evokes in its victim intense feelings of humiliation and terror" and asking: "Might there not exist a right to the integrity of one's own body, that not even the state's interests in punishing may override?”).

${ }^{148}$ See, e.g., Hernan Reyes, The Worst Scars Are In the Mind: Psychological Torture, 89 INT'L REV. RED CROSS 591, 594-616 (2007), http://www.961.ch/eng/assets/files/other/irrc-867reyes.pdf (defining psychological torture and detailing various methods of psychological torture, along with their effects); Jeffrey L. Metzner \& Jamie Fellner, Solitary Confinement and Mental Illness in U.S. Prisons: A Challenge for Medical Ethics, 38 J. AM. ACAD. PSYCHOL. 104, 104 (2010) ("Solitary confinement is recognized as difficult to withstand; indeed, psychological stressors such as isolation can be as clinically distressing as physical torture.").

149 See, e.g., J. D. Mabbott, Professor Flew on Punishment, 30 PhILosophy 256, 257 (1955) ("Most punishments nowadays are not afflictions of suffering, either physical or mental. They are the deprivation of a good.”); Geoffrey Scarre, Corporal Punishment, 6 Ethical Theory \&Moral Prac. 295, 297 (2003) ("Some punishments (e.g. imprisonment with hard labour) involve both a corporal and a non-corporal element (the hard labour and the incarceration respectively)."); see also Alexander A. Reinert, Release as Remedy for Excessive Punishment, 53 WILliAM \& MARY L. REV. 1575, 1589-90 (forthcoming, 2012), available at http:ssrn.com/abstract-2021398 (observing that terms of incarceration will almost always survive scrutiny under the Eighth Amendment).

${ }^{150}$ See Sharon Dolovich, Cruelty, Prison Conditions, and the Eighth Amendment, 84 N.Y.U L. Rev. 881, 915-16 (2009) ("To force prisoners to live in constant fear of violent assault, under conditions in which many of the most vulnerable among them can expect that fear to be realized, is to inflict a form of physical and psychological suffering akin to torture. It is plainly cruel to punish criminal offenders with the strap, with rape, or with any other form of brutal corporal treatment. And for the same reason, the state may not place incarcerated offenders in a position of ongoing vulnerability to assault by predatory prisoners, thus creating conditions that would amount to the same thing."); David Garland, supra note 146, at 149 ("The crucial difference 
*DRAFT: PLEASE DO NOT CITE WITHOUT PERMISSION

MAY 3, 2013

then, when the foreseeable risk of experiencing serious physical or psychological harm in prison surpasses some threshold, ${ }^{151}$ incarceration under a certain set of conditions should no longer be a permissible punishment option. Thus, when a judge believes that incarceration under standard conditions would pose an unacceptable risk of serious harm to a particular offender, the judge should be authorized to select an alternative sanction of roughly equivalent punitive bite or to modify the offender's conditions of confinement so that incarceration is a morally tolerable option. ${ }^{152}$

\section{B. Rehabilitative Rationales}

In addition, two strains of rehabilitative thought could inspire the consideration of mental disorder and vulnerability. The first view echoes the understanding of punishment dominant in the United States from the World Wars through the 1970s: the state, through criminal punishment, should seek to identify and treat the underlying causes of an individual's criminality. ${ }^{153}$ Professor Francis Allen has described the "rehabilitative ideal" in this way:

It is assumed, first, that human behavior is the product of antecedent causes. These causes can be identified as part of the physical universe[,] and it is the obligation of the scientist to

between corporal punishments that are banned, and other punishments - such as long-term imprisonment that are routinely used, is not a matter of the intrinsic levels of pain and brutality involved. It is a matter of the form which that violence takes, and the extent to which it impinges on public sensibilities.”).

151 When that threshold exists will depend on the particularized risk of serious harm that prison poses to an individual offender. See Johnston, Vulnerability, supra note 12, at 180 ("Statistical risk alone, however, may not merit a change in sentencing."); $c f$. Kenneth W. Simons, Statistical Knowledge Deconstructed, 92 B. U. L. REV. 1, 6 (2012) (distinguishing between statistical and individualized knowledge for purposes of culpability determinations). Individuals with serious mental illnesses often will be able to prove that they face a particularized risk of serious harm from incarceration, beyond background statistical rates. In many instances an individualized showing will be possible given prior patterns of behavior, personal history of abuse, and the constellation of other risk factors that an individual may have that can be brought to a judge's attention at a sentencing hearing.

152 See Johnston, Vulnerability, supra note 12, at 216-221 (describing how just deserts theory can offer guidance for discerning alternative punishments of roughly equivalent punitive onerousness).

153 See Richard C. Boldt, Rehabilitative Punishment and the Drug Treatment Court Movement, 76 WASH. U. L. Q. 1205, 1219-20 (1998); Francis A. Allen, THE DECLINE OF THE Rehabilitative Ideal: Penal Policy AND Social PuRpose 2 (1981) (1979 Storrs Lectures on Jurisprudence) ("[T]he rehabilitative ideal is the notion that a primary purpose of penal treatment is to effect changes in the characters, attitudes, and behavior of convicted offenders, so as to strengthen the social defense against unwanted behavior, but also to contribute to the welfare and satisfaction of offenders.”). 
*DRAFT: PLEASE DO NOT CITE WITHOUT PERMISSION

MAY 3, 2013

discover and to describe them with all possible exactitude. Knowledge of the antecedents of human behavior makes possible an approach to the scientific control of human behavior. Finally, . . . it is assumed that measures employed to treat the convicted offender should serve a therapeutic function, that such measures should be designed to effect changes in the behavior of the convicted person in the interest of his own happiness, health, and satisfaction and in the interest of social defense. ${ }^{154}$

While the rehabilitative ideal did not specify a single theory of crime causation, ${ }^{155}$ psychiatrist Karl Menninger, ${ }^{156}$ Benjamin Karpman, ${ }^{157}$ and others, ${ }^{158}$ embraced a medical model of crime. ${ }^{159}$ According to this theory, criminal behavior is symptomatic of mental illness or personality disorder. ${ }^{160}$ In essence, offenders are considered "sick" and in need of a state-coerced "cure" to address their underlying sources of criminality. ${ }^{161}$ Identification and treatment of an inmate's mental disorder, under this perspective, may be essential to restoring the offender to a law-abiding citizen. ${ }^{162}$ Evidence suggests, however, that offenders with major

154 Francis A. Allen, Criminal Justice, Legal Values, and the Rehabilitative Ideal, in PunishmENT AND REHABILITATION 172-85, 173 (Jeffrie G. Murphy ed. 1973).

${ }^{155}$ ALLEN, DECLINE OF THE REHABILITATIVE IDEAL, supra note 153, at 3.

156 See, e.g., Karl Menninger, Therapy, Not Punishment, in PunISHMENT AND Rehabilitation, supra note 154, at 132; KARL MEnNinger, The Crime of Punishment (1968); Karl Menninger, Medicolegal Proposals of the American Psychiatric Association, 19 J. CRIM. L., CRIMINOLOGY \& POLICE SCI. 367 (1928).

${ }^{157}$ See, e.g., Benjamin Karpman, Criminal Psychodyamics: A Platform, in PUNISHMENT AND ReHABILITATION, supra note 154, at 118; BenJamin KARPMAN, The SEXUAl OFFENDER AND His OfFenses (1954); Benjamin Karpman, CASe Studies in the Psychopathology of CRime (1947).

${ }^{158}$ See, e.g., BARBARA WOOTTON, CRIME AND THE CRIMINAL LAW (1963) (arguing that the criminal justice system should serve preventative, not punitive, ends and treat the origins of criminality).

${ }^{159}$ For a description of the tenets and evolution of therapeutic rehabilitation, see E. RoTMAN, Beyond Punishment: A NeW View on the Rehabilitation of CRiminal OfFenders 60-63 (1990). Most of the criticism of rehabilitation in the 1970s was aimed at the therapeutic model of rehabilitation. Id. at 5.

${ }^{160}$ See Jeffrie G. Murphy, Introduction, in Punishment and Rehabilitation, supra note 154, at 1, 5; Karpman, supra note 157, at 119 (arguing that "criminality is but a symptom of insanity”).

${ }^{161}$ See RotMAn, supra note 159, at 5.

${ }^{162}$ As I have argued elsewhere, these views, or similar ones, inspire therapeutic jurisprudence and modern problem-solving courts, including mental health courts. See Johnston, Theorizing Mental Health Courts, 89 WASH. U. L. REV. 519, 547-51 (2012); see also Boldt, supra note 153, at 1212-18, 1226-34, 1237, 1243-45 (arguing that, while drug treatment courts do not occasion a full 
*DRAFT: PLEASE DO NOT CITE WITHOUT PERMISSION

MAY 3, 2013

mental disorder often retain the ability to make rational choices and that their criminal behavior may reflect varying motivations. ${ }^{163}$ A less radical and perhaps more supportable view is that the treatment and control of symptoms associated with mental illness is necessary to allow an individual with a serious mental illness to benefit from programming, which has been shown by some studies to hold rehabilitative potential. ${ }^{164}$

\section{Collateral Benefits}

Finally, collateral benefits would attend a judge's consideration and accommodation of offender vulnerability at sentencing. Expressing concern for individuals' actual prison experience would serve as a means to honor offenders' personhood and inherent worth. ${ }^{165}$ Authorizing judges to consider, acknowledge, and respond to foreseeable, substantial risks of harm would expose prison conditions and correctional mental health services to the light of day and should prompt the reform of both. ${ }^{166}$ Sustained attention to the plight of vulnerable populations should also increase consideration of and demand for alternative sentencing options, such as home detention with electronic monitoring, halfway houses, inpatient and outpatient mental health treatment, and mandatory community service. Many of these noncarceral penalties are much less expensive than prison, which could offer welcome cost savings. ${ }^{167}$ Finally, by factoring vulnerability into sentencing, judges would be active participants in the most important exercise of all: making our criminal justice system more just and less cruel.

return to the rehabilitative ideal, the courts possess multiple rehabilitative elements and should thus be subjected to the critiques levied against rehabilitation in the late 1960s and 1970s); JAMES L. Nolan, JR., Reinventing Justice: The AmERiCAn Drug Court Movement 185-208 (2001); James L. Nolan, Jr., Redefining Criminal Courts: Problem-Solving and the Meaning of Justice, 40 AM. CRIM. L. REV. 1541, 1554-63 (2003) (arguing that drug treatment courts represent in many ways a return to a rehabilitative theory of punishment).

163 See Johnston, Theorizing Mental Health Courts, supra note 162, at 558-61 (discussing social scientists' views of the varying motivations for crimes committed by individuals with serious mental illnesses).

${ }^{164}$ See THIGPEN ET AL., supra note 1 , at 8.

165 See Johnston, Vulnerability, supra note 12, at 195-97.

166 See Alice Ristroph, Sexual Punishments, 15 Colum. J. Gender \& L. 139, 141 (2006) ("[T]o the extent that sexual coercion in prison cannot be eliminated, we should make that fact part of debates about the appropriate use of imprisonment as a penalty.”).

167 See Linh VuOng, et AL., NAtional Counsel on Crime And Delinquency, The EXTRAVAGANCE OF IMPRISONMENT REVISITED http://www.nccdglobal.org/sites/default/files/publication_pdf/specialreport-extravagance.pdf (analyzing incarcerated populations in the U.S, and four states to determine the percentage of nonserious offenders and concluding that a significant cost savings could be realized if these offenders were sentenced to noncarceral alternatives). 
*DRAFT: PLEASE DO NOT CITE WITHOUT PERMISSION

MAY 3, 2013

\section{Jurisdictions' Current Treatment of Vulnerability as a Mitigating Factor}

Recognizing that incarceration entails excessive suffering for certain offenders and thus may impede the desired ends of punishment, many jurisdictions allow a judge to consider an offender's likely hardship when deciding whether to order a sentence of incarceration or determining its duration. ${ }^{168}$ While these efforts are salutary, they do not go far enough to ensure that vulnerable offenders receive humane or proportionate sentences.

A number of states and the federal government recognize vulnerability or excessive offender hardship as a mitigating factor for purposes of sentencing. ${ }^{169}$ Many state statutes frame the mitigating factor in general, source-neutral terms. Arkansas, Hawaii, Indiana, Montana, Louisiana, North Dakota, New Jersey, and Utah, for instance, authorize judges to consider when imprisonment would result in "undue" or "excessive" hardship to the offender. ${ }^{170}$ Other states specify that

${ }^{168}$ See supra note 9 (stressing that explicit authorization is most critical in jurisdictions with determinate sentencing regimes).

169 In addition, states may have a "catch-all” provision, which allows courts to mitigate an individual's sentence when it feels that doing so is necessary for the ends of justice. See, e.g., ARIZ. REV. STAT. ANN. § 13-701(E)(6) (West 2012) (providing that the court shall consider "[a]ny other factor that is relevant to the defendant's character or background or to the nature or circumstances of the crime and that the court finds to be mitigating”).

170 See, e.g., ARK. CODE ANN. § 5-4-301(c)(11) (West 2012) (authorizing the trial court to consider, in favor of suspension or probation for most criminal offenses, whether " $\mathrm{t}] \mathrm{he}$ imprisonment of the defendant would entail excessive hardship to the defendant or to a dependent of the defendant”); HAW. REV. STAT. § 706-621(2)(i) (West 2012) ("The court, in determining whether to impose a term of probation, shall consider [whether] . . . [t]he imprisonment of the defendant would entail excessive hardship to the defendant or the defendant's dependents[.]"); IND. CODE ANN. 35-38-1-7.1(b)(10) (West 2012) ("The court may consider the following factors as mitigating circumstances or as favoring suspending the sentence and imposing probation: . . . Imprisonment of the person will result in undue hardship to the person or the dependents of the person.”); LA. CODE. CRIM. PROC. ANN. ART. 894.1.B(31) (West 2012) (providing that courts, when deciding whether to suspend a sentence and impose probation, should consider whether "[t]he imprisonment of the defendant would entail excessive hardship to himself or his dependents”); MonT. CODE ANN. § 46-18-225(j) (West 2012) ("Prior to sentencing a nonviolent felony offender to whom 46-18-219 does not apply to a term of imprisonment in a state prison, the sentencing judge shall take into account whether: . . . imprisonment of the offender would create an excessive hardship on the offender or the offender's family.”); N.J. STAT. ANN. § 2C:441(b)(11) (West 2012) (listing, as a criterion for the appropriateness of imprisonment as a sanction, whether "imprisonment of the defendant would entail excessive hardship to himself or his dependents”); N.D. CENT. CODE ANN. § 12.1-32-04(11) (West 2011) ) (suggesting that the trial court should consider, in deciding whether to order imprisonment, whether " $[\mathrm{t}]$ he imprisonment of the defendant would entail undue hardship to himself or his dependents”); Utah Sentencing Commission, 2012 Adult Sentencing and Release Guidelines (Form 2, page 12), http://www.sentencing.utah.gov/Guidelines/Adult/2011\%20Adult\%20Sentencing\%20and\%20Rele ase\%20Guidelines.pdf (specifying as a mitigating factor that may "compel deviation from the 
*DRAFT: PLEASE DO NOT CITE WITHOUT PERMISSION

MAY 3, 2013

mitigation may be appropriate when the likely hardship stems from a specific source. One example is Illinois, which provides that a sentencing judge should consider, as a factor in favor of withholding or minimizing a sentence of imprisonment, whether "the imprisonment of the defendant would endanger his or her medical condition." 171 The District of Columbia, on the other hand, allows a judge to sentence outside the voluntary sentencing guidelines when "the court determines that the defendant, by reason of obvious and substantial mental or physical impairment or infirmity, cannot be adequately protected or treated in any available prison facility."172

Currently, a judge's consideration of an offender's likely hardship in prison may affect an offender's sentence in one of two ways. First, offender hardship may militate towards a suspended sentence of incarceration with probation. ${ }^{173}$ For example, New Jersey and Louisiana authorize judges to consider, when determining the appropriateness of imprisonment as a sanction, whether "imprisonment of the defendant would entail excessive hardship to

guidelines" when "[i]mprisonment would entail excessive hardship on offender or dependents"); see also 9 Minn. PraC., CRiminal LAW \& Procedure §36.30(j) (3d ed.) (authorizing, though case law, a dispositional departure where defendant's youth, immaturity, or old age make her vulnerable to victimization in a prison setting); see generally Carissa Byre Hessick, Ineffective Assistance at Sentencing, 50 B.C. L. REV. 1069, 1120 \& n.284 (2009) (characterizing whether imprisonment would constitute a hardship for the offender as a mitigating factor that has been considered "particularly powerful in various jurisdictions" and listing some jurisdictions).

171730 Ill. COMP. StAT. ANN. § 5 / 5-5-3.1(a)(12) (West 2012). Other states classify an offender's need for treatment as a mitigating factor. See, e.g., FLA. STAT. ANN. § 921.0026(2) (West 2012) (treating, as a mitigating circumstance, when "[t]he defendant requires specialized treatment for a mental disorder that is unrelated to substance abuse or addiction or for a physical disability, and the defendant is amenable to treatment”), HAW. REv. STAT. § 706-606(2)(d) (West 2012) (charging the court to consider, when imposing a sentence, the need "[t]o provide the defendant with needed educational or vocational training, medical care, or other correctional treatment in the most effective manner"); OR. ADMIN. R. 213-008-0002(1)(a)(I) (2012) (listing, as a mitigating factor that may be considered in determining whether substantial and compelling reasons for a departure exist, when "[t]he offender is amenable to treatment and an appropriate treatment program is available to which the offender can be admitted within a reasonable period of time; the treatment program is likely to be more effective than the presumptive prison term in reducing the risk of offender recidivism; and the probation sentence will serve community safety interests by promoting offender reformation.”).

172 Dist. of Columbia Sentencing \& Criminal Code Revision COMm’n, Voluntary SENTENCING GUIDELINES MANUAL §5.2.3(8) (2012).

${ }^{173}$ See supra note 170. Professor Richard Frase has argued that mitigated departures for unamenability to prison and amenability to probation, in the context of the Minnesota sentencing scheme, may be consistent with limiting retributivism. See Richard S. Frase, Sentencing Reform in Minnesota, Ten Years After: Reflections on Dale G. Parent's Structuring Criminal Sentences: The Evolution of Minnesota's Sentencing Guidelines, 75 MinN. L. REV. 727, 742-46 (1991). 
*DRAFT: PLEASE DO NOT CITE WITHOUT PERMISSION

MAY 3, 2013

himself . . ."174 In these states, offender hardship is one factor, among many, to weigh when deciding whether an executed sentence of imprisonment or a suspended sentence with probation is the more appropriate punishment for a given offender. Perhaps not surprisingly, a review of case law suggests that the mitigating factor typically only leads to an order of probation for those offenders who have limited aggravating factors, no prior criminal history, or who would otherwise be amenable to probation. ${ }^{175}$ In states that limit the mitigating factor to the probation/incarceration calculus, ${ }^{176}$ courts lack the means to recognize, or mitigate, the vulnerability of offenders who fall outside this narrow band and receive sentences of incarceration.

Other jurisdictions, including the federal government, ${ }^{177}$ allow courts to shorten the prison terms of offenders likely to suffer extreme hardship when

174 LA. Code. Crim. Proc. AnN. ART. 894.1.B(31) (West 2012); N.J. StAT. AnN. § 2C:441(b)(11) (West 2012).

175 See, e.g., State v. Evers, 815 A.2d 432, 451-55 (N.J. 2003); State v. Jarbath, 555 A.2d 559, 561, 564, 559 (N.J. 1989) (finding that the extreme hardship of the mentally retarded offender, who had suffered almost daily severe abuse in prison and had attempted suicide, outweighed the deterrent value of her carceral sentence, where no aggravating factors applied and the defendant was unlikely to commit future violent acts); State v. E.R., 641 A.2d 1072, 1073, 1077 (N.J. Super. App. Div.1994) (approving a probationary sentence upon resentencing where the offender was amenable to probation, would suffer extreme hardship in prison, and was not at risk of committing another offense, as he was likely to die within a few months from AIDS); see also State v. Wright, 310 N.W.2d 461, 462-63 (Minn. 1981) (upholding the dispositional departure where the defendant was "more child than man" and would be victimized easily in prison, no appropriate psychiatric institution was available, the defendant was amenable to individualized treatment in a probationary setting, and the defendant would pose little threat to society if supervised through out-patient treatment); State v. Hitz, 1990 WL 115108, *2 (Minn. App.) (affirming dispositional departure based on reports that the defendant would be suicidal if the sentence were executed and that his mental disorder rendered him more amenable to probation and treatment than prison); Rachel Konforty, Efforts to Control Judicial Discretion: The Problem of AIDS and Sentencing, 1998 AnN. SuRV. AM. L. 49, 64-65, 92-94 (1998) (describing New Jersey’s statutory framework and its application within the context of AIDS and HIV).

176 Minnesota allows vulnerability to abuse-an offender-related trait, as opposed to an offense-related characteristic - to support a dispositional departure in the form of a stayed sentence, but not a durational departure in the form of a reduced term of years in prison. See State v. Behl, 573 N.W.2d 711, 713-14 (Minn. App. 1998) (holding that trial court properly refused to consider offender-related mitigation evidence of amenability to probation because, while such evidence may be used to justify a dispositional departure, it cannot serve as the basis for durational departure).

177 See Mary Sigler, Just Deserts, Prison Rape, and the Pleasing Fiction of Guideline Sentencing, 38 ARIZ. ST. L.J. 561, 571-74 (2006) (describing the operation of downward departures on the basis of vulnerability under the federal sentencing guidelines). Under the U.S. Sentencing Guidelines, mental and emotional conditions are ordinarily irrelevant in determining whether a sentence should fall outside the sentencing range established by the Guidelines for a criminal offense. See United States Sentencing Commission, Guidelines Manual § 5 H1.3 (2010). 
*DRAFT: PLEASE DO NOT CITE WITHOUT PERMISSION

MAY 3, 2013

incarcerated. ${ }^{178}$ These jurisdictions, in effect, allow a sentencing "discount" for the increased severity of an offender's carceral sentence, as compared to the anticipated prison experience of a standard offender. ${ }^{179}$ Judges in these jurisdictions cannot tailor the conditions of confinement in order to reduce the vulnerable offender's risk of harm. This has led to charges, such as those raised by Professor Mary Sigler, that federal courts which grant downward departures for extreme vulnerability to victimization are, in practice, sentencing vulnerable defendants to prison terms "at rape" or to terms involving other forms of inhumanity or cruelty. ${ }^{180}$

Thus, jurisdictions' current approaches, while a definite improvement over sentencing systems that discourage judges from modifying presumptive sentences on the basis of their likely injurious effect, do not go far enough. Although intermediate sanctions such as weekends in jail and laborious community service may provide appropriate (and cost-effective) ${ }^{181}$ penalties for many offenders, ${ }^{182}$ imprisonment will likely remain a necessary sanction for the most serious

However, under Guidelines Section 5H1.3, an offender's vulnerability due to mental or emotional conditions may justify a downward departure so long as such conditions "are present to an unusual degree and distinguish the case from the typical cases covered by the guidelines." U.S.S.G. § 5H1.3 (2010). Some courts have also relied on Guidelines Sections 5K2.0, 5H1.4, and 5K2.13 to grant downward departures on the basis of suspected or demonstrated hardship in prison. See Johnston, Vulnerability, supra note 12, at 181-82 \& nn.172-75.

178 See, e.g., Kern v. State, 884 N.E.2d 440, *2 (Ind. Ct. App. 2008) (holding that the trial court afforded sufficient weight to defendant's back pain and pleurisy as a mitigating factor when it sentenced her to less than the maximum sentence of incarceration); Moyer v. State, 796 N.E.2d 309, 314 (Ind. Ct. App. 2003) (finding that the trial court abused its discretion in failing to consider the defendant's history of lymphoma, malignancy of the larynx, recurring tumors, pulmonary disease, reliance on a breathing apparatus, and need for frequent tracheal cleanings and sterile catheters in sentencing and electing to reduce the defendant's sentence from 40 to 24 years in prison).

${ }^{179}$ See Johnston, Vulnerability, supra note 12, at 201-03.

${ }^{180}$ Sigler, supra note 177 , at 573.

181 See Robert E. Harlow, et al., The Severity of Intermediate Penal Sanctions: A Psychophysical Scaling Approach for Obtaining Community Perceptions, 11 J. QUANTITATIVE CRIMINOLOGY 71, 72 (1995) ("Intermediate sanctions offer the promise of reducing overcrowding, thereby enabling the prison system to retain violent criminals for nearer the full term of their sentences and, also, to reduce costs, given the high expense of imprisonment.”); supra note 167.

182 See Michael Tonry, Sentencing Matters 127 (1996) ("There is a need for credible, enforceable sanctions between prison and probation that can provide appropriate deserved penalties for offenders convicted of mid-level crimes.”); Paul Robinson \& John M. Darley, The Role of Deterrence in the Formulation of Criminal Law Rules: At Its Worst When Doing Its Best, 91 GEO L.J. 949, 996 (2003) ("For less serious crimes there are a number of alternatives to prison sentences that people would perceive as having a punitive 'bite' comparable to that of a short prison term ... such as home confinement, labor-intensive community service, weekends in jail, and fines.”). 
*DRAFT: PLEASE DO NOT CITE WITHOUT PERMISSION

MAY 3, 2013

offenses. ${ }^{183}$ Assuming that incarceration is the only appropriate sanction for some offenses, offenders with serious mental illnesses who commit these offenses with the requisite mental state should endure incarceration, but only under conditions that are humane and that approximate, as closely as possible, the conditions that a non-vulnerable person would experience if confined. ${ }^{184}$ The next two Parts explore how legislatures could expand judges' control over the terms and conditions of carceral sentences in response to the foreseeable hardship of seriously disordered offenders to better ensure that their sentences serve the legitimate aims of punishment.

\section{Sentencing as a Means to Flag Offenders with Serious Mental Disorder}

One source of concern regarding an offender with a serious mental disorder is that correctional authorities will fail to detect his disorder, resulting in a withholding of treatment and perhaps his placement in an inappropriate environment. As previously discussed, correctional officials conduct mental health screens at intake as a form of triage, based largely on information revealed through a short interview. ${ }^{185}$ Often only a subset of individuals receives comprehensive assessments by a psychologist or psychiatrist. ${ }^{186}$ One contribution that judges could make to improve the prison experience of seriously disordered defendants would be to ensure that these individuals receive comprehensive mental health evaluations by qualified mental health professionals at intake, thus improving their likelihood of receiving treatment and appropriate housing.

\footnotetext{
183 Some commentators have opined that incarceration is the only sanction severe enough to communicate the degree of censure warranted for commission of serious offenses. See, e.g., VON HIRSCH, supra note 147, at 111 ("One reason for preferring incarceration is that we have not found another satisfactory severe punishment.”); Harlow, et al., supra note 181, at 86 (noting that survey respondents viewed 18 months of intermediate sanctions as equivalent to 6 months imprisonment, but that "[n]o intermediate sanctions were seen as equivalent to prison terms of 2 years or more”). In addition, incarceration may be the only sanction likely to serve as an effective general or specific deterrent. See David C. Anderson, Sensible Justice: Alternatives to Prison 19 (1998) (noting that a central principal of sentencing should be to "reserve the most serious confinement and punishment for the most serious criminals"); id. at 144 (stating that alternative sanctions are preferable but that the following three reasons justify incarceration: "to affirm the gravity of the crime, to deter the criminal and others who are like-minded, or because other sanctions have proved insufficient”).

${ }^{184}$ See Bonnie P. Tucker, Deaf Prison Inmates: Time to Be Heard, 22 LOY. L. A. L. REV. 1, 14 (1988-89) (arguing that the solution to the problem of the harsher prison experience of deaf prisoners "lies in equalizing - to the extent practicable - the conditions of confinement for deaf and hearing prisoners”).

185 See supra text accompanying notes 55-62.

${ }^{186}$ See supra notes 30-32 and accompanying text.
} 
This reform could take at least two forms. One option would be for a legislature to provide that, when a sentencing judge includes a finding in his sentencing order that an individual has a serious mental disorder, the correctional agency must ensure that the prisoner receives a comprehensive mental health evaluation, by a qualified and licensed psychologist or psychiatrist, within a certain number of hours of admission to an intake facility. Alternatively, a legislature could permit the judge to include such an evaluation as a condition of his sentence. In this way, a judge's sentencing order could eliminate the uncertainty of the screening process for a given offender, supplying the "urgency" necessary to trigger a comprehensive assessment and accelerating the timing of the assessment. ${ }^{187}$

As described below, a sentencing judge's assessment of a defendant's mental health may be more likely to be accurate than that of an intake evaluator, ${ }^{188}$ given the judge's familiarity with the defendant and the information that the defendant may bring to the judge's attention during the sentencing hearing. Therefore, factoring a judge's assessment of a defendant's mental health into the correctional evaluation process should result in the latter's being more informed, more efficient, and more accurate. It also should result in fewer disordered individuals slipping through the cracks. In this way, a judge's finding of mental disorder could serve as a more appropriate mechanism to secure the primary benefit currently obtained through a guilty but mentally ill verdict.

\section{A. Relative Accuracy of Judicial Findings of Mental Disorder}

A judge at sentencing is likely to have a much more nuanced understanding of the offender-including his mental health history and current mental health status - than officials at intake. ${ }^{189}$ Because an individual's capacity to understand reality and conform his conduct to the dictates of the law may implicate his culpability for past acts and his ability to participate in the adversarial process, multiple steps are built into the criminal justice process to allow for consideration of a defendant's mental illness. A judicial official will consider an offender's mental health when determining bail and pretrial release

187 See supra note 30 and accompanying text.

188 Since a judge is not a mental health professional, his assessment (though likely based on psychiatric opinions) may be less likely to be accurate than that of a clinical or forensic psychologist or psychiatrist. Therefore, this Article merely proposes that a judicial finding of serious mental disorder trigger a comprehensive assessment by a qualified mental health professional; it does not recommend that the judicial finding substitute for, or obviate the need for, a later assessment by a mental health professional.

189 But see supra note 188 (noting that a judge's finding of mental disorder may be less accurate than that of a psychologist or psychiatrist). 
*DRAFT: PLEASE DO NOT CITE WITHOUT PERMISSION

MAY 3, 2013

conditions. ${ }^{190}$ Mental disorder will be a key focal point of any challenge to the accused's competence to stand trial ${ }^{191}$ or his decisional competence to make the few choices allocated to him, such as whether to waive his right to counsel and plead guilty. ${ }^{192}$ If the accused pleads not guilty, he may use evidence of mental disorder to advance an insanity defense, demonstrate a lack of intent, or perhaps further other defenses such as provocation or self-defense. ${ }^{193}$ In addition, many state statutes require probation officers to include an offender's mental health history in the presentencing report created for the court, ${ }^{194}$ and others permit officers to include this information if relevant to the appropriateness of sentencing options. ${ }^{195}$ Thus, in the case of an offender with a serious mental illness, at the

190 See John Clark \& D. Alan Henry, Office of Justice Programs, Dep’t of Justice, Pretrial SERVICES Programming at THE START OF THE 21ST CENTURY: A SURVEy OF Pretrial SERVICES PROGRAMS 13 (2003), available at http://www.napsa.org/publications/prog21stcent.pdf (noting that pretrial services officers typically provide judges with information about defendants' mental health statuses for consideration in bail determinations).

191 See Dusky v. United States, 362 U.S. 402, 402 (1960) (establishing that, to stand trial, a defendant must possess "sufficient present ability to consult with his lawyer with a reasonable degree of rational understanding" and "a rational as well as factual understanding of the proceedings against him”); see also Drope v. Missouri, 420 U.S. 162, 171 (1975). Courts have interpreted this competency standard to require that a defendant be able to appreciate his status as a defendant in a criminal prosecution and understand the charges, the purpose of the criminal process, and the purpose of the adversary system, including the role played by defense counsel. See Richard J. Bonnie, The Competence of Criminal Defendants: Beyond Dusky and Drope, 47 U. MiAMi L. REV. 539, 554 \& n.62, 63 (1993).

192 See Bonnie, supra note 191, at 553-60 (exploring the concept of decisional competence).

${ }^{193}$ Prior to consideration of vulnerability at the sentencing phase, a defendant's mental illness may reduce his culpability at the guilt phase of his proceeding. Others have argued for the expansion or reduction of these defensive strategies. Compare Christopher Slobogin, An End to Insanity: Recasting the Role of Mental Disability in Criminal Cases, 86 VA. L. REV. 1199, 1246 (2000), with Laura Reider, Toward a New Test For Insanity Defense: Incorporating The Discoveries of Neuroscience Into Moral and Legal Theories, 46 UCLA L. REV. 289, (1998). This Article takes no position on these issues.

194 See, e.g., 730 ILL. COMP. STAT. ANN. 5 / 5-3-2(a)(1) (West 2012) ("In felony cases, the presentence report shall set forth the defendant's history of delinquency or criminality, physical and mental history and condition, family situation and background, economic status, education, occupation and personal habits. .. .”); IOWA CODE ANN.§ 901.3(8) (West 2012) (“If a presentence investigation is ordered by the court, the investigator shall promptly inquire into . . .[w]hether the defendant has a history of mental health or substance abuse problems.”); N.Y. CRIM. PROC. LAW $\S 390.20$ (McKinney 2010) (requiring pre-sentence investigation and report for all offenders convicted of felonies and certain offenders convicted of misdemeanors); id. at $\$ 390.30$ (requiring that pre-sentence report include information regarding defendant’s mental health).

195 See, e.g., MonT. CoDE. ANN. § 46-18-112(3) (2011) ("The court may, in its discretion, require that the presentence investigation report include a physical and mental examination of the defendant.”); FED. R. CRIM. P. 32(c)(1)(A) (“The probation officer must conduct a presentence 
*DRAFT: PLEASE DO NOT CITE WITHOUT PERMISSION

MAY 3, 2013

moment of sentencing a judge likely will be familiar with the defendant's mental health history and current mental health status. A judge should be adept at considering both evidence of mental disorder and its likely effect on an individual's future prison experience, as individualized risk assessment is a routine aspect of judging. ${ }^{196}$

In addition, unlike in the intake setting, a defendant has a number of rights that bear on his ability to bring relevant evidence of mental disorder and vulnerability to the attention of the sentencing judge. An indigent defendant has a Sixth Amendment right to appointed counsel at a sentencing hearing, ${ }^{197}$ when his sentence may include suspended or actual incarceration. ${ }^{198}$ In addition, defendants

investigation and submit a report to the court before it imposes sentence"); id. at 32(d)(1)(D)(i) ("The presentence report must identify any factor relevant to the appropriate kind of sentence").

196 Judges make individualized risk assessments in a number of contexts, including bail determinations, capital sentencing, and sex offender sentencing. See, e.g., Carol Steiker, Foreword: The Limits of the Preventive State, 88 J. CRIM. L. \& CRIMINOLOGY 771, 774 (1998) (observing that the use of actuarial instruments is most prevalent in furthering our nascent mission as a "preventive state"); Jonathan Simon, Reversal of Fortune: The Resurgence of Individual Risk Assessment in Criminal Justice, 1 AnN. REV. LAW \& Soc. SCI. 397, 398 (2005) (finding that "risk assessment has become a largely uncontested aspect of a much expanded criminal process, and it has been entrusted to a range of criminal justice actors," including judges); Cynthia A. Mamalian, U.S. Dep't of Justice, Pretrial Justice Ins., State of the Science OF PRETRIAL RISK ASSESSMENT 6 (2011), available at http://www.pretrial.org/Setting\%20Bail\%20Documents/PJI\%20State\%20of\%20the\%20Science\% 20Pretrial\%20Risk\%20Assessment\%20(2011).pdf (noting that the availability of "objective research-based" risk assessment tools has better equipped judges "to assign more rational conditions of release or detention").

${ }^{197}$ Mempa v. Rhay, 389 U.S. 128, 134 (1967) (stating that "appointment of counsel for an indigent is required at every stage of a criminal proceeding where substantial rights of a criminal accused may be affected ... [and that due to] the critical nature of sentencing ... the right to counsel applies at sentencing").

${ }^{198}$ See Scott v. Illinois, 440 U.S. 367, 369 (1979); Alabama v. Shelton, 535 U.S. 654, 654-55 (2002). In dicta, the U.S. Supreme Court has also suggested that indigent defendants have a right to appointed counsel in all felony cases. Nichols v. United States, 511 U.S. 738, 746 (1994). Though the Supreme Court has never addressed the precise scope of the right, defendants appear to have a right to effective assistance of counsel at noncapital sentencing proceedings, as defined by the two-part test delineated in Strickland v. Washington. See Strickland v. Washington, 466 U.S. 668, 687 (1984) (stating that the defendant must show first "that counsel's performance was deficient" and second "that the deficient performance prejudiced the defense"); Glover v. United States, 531 U.S. 198, 203 (2001) (noting that even a minimal amount of additional jail time resulting from counsel's deficient performance constitutes prejudice to the defendant); see also Lockhart v. Fretwell, 506 U.S. 364 (1993) (holding that, even though the defendant would not have received the death penalty had his lawyer objected, the defendant was not unconstitutionally prejudiced where the sentence was not "fundamentally unfair or unreliable" in light of a subsequent change in the relevant case law). Commentators have worked to delineate standards for evaluating ineffectiveness claims in the context of non-capital sentencing. See Hessick, supra note 170, at 1080, 1086 (noting that "[t]he Supreme Court has not yet decided what standard applies to 
*DRAFT: PLEASE DO NOT CITE WITHOUT PERMISSION

MAY 3, 2013

may have a right to review and respond to assertions included in a presentence report. ${ }^{199}$ In non-capital cases, states typically allow defense counsel the opportunity to challenge or supplement information in a presentence report or, if no such report is compiled or it is not disclosed, gather and submit to the court any evidence concerning a defendant's mental health history, status, or prognosis that counsel believes should result in mitigation or the adoption of an alternative sentence. ${ }^{200}$ Some courts have held that a defendant has a constitutional right to allocution at sentencing, ${ }^{201}$ and defendants may have a due process right to call critical witnesses to testify on their behalf. ${ }^{202}$ Also, while federal courts take the position that defendants have no constitutional right to confront and cross-

ineffective assistance at sentencing claims in discretionary non-capital sentencing systems" and suggesting that a heightened standard is inappropriate and, instead, "any defendant who can demonstrate a reasonable probability that her sentence was increased by any amount of actual jail time should be deemed to have satisfied the prejudice prong of her ineffective assistance claim”); Note, Prejudice and Remedies: Establishing a Comprehensive Framework for Ineffective Assistance Length-of-Sentence Claims, 119 HARV. L. REV. 2143, 2152 (2006) (suggesting that "Strickland should be understood to require only a reasonable probability of a shorter sentence for length-of-sentence claims based on errors made at sentencing in a discretionary regime”).

${ }^{199}$ Gardner v. Florida, 430 U.S. 349, 362 (1977). The U.S. Supreme Court has not determined whether this right extends to presentence reports in non-capital cases.

200 See ABA STANDARDS FOR CRIMINAL JUSTICE, DEFENSE FUnCTION (3d ed. 1993), available http://www.americanbar.org/publications/criminal_justice_section_archive/crimjust_standards_df unc_blkold.html (standard 4-8.1 for sentencing); see also Fla. R. Crim. P. 3.713 (requiring the sentencing court, upon motion of the defendant, to include in the presentence report a mental examination of the defendant that may be relevant to the sentencing decision); N.Y. CRIMINAL PROCEDURE LAW $\S \S 390.30-.40$ (McKinney 2011) (stating that the defendant may, at any time prior to the pronouncement of sentence, file with the court a written memorandum setting forth any information he may deem pertinent to the question of his sentence, including information related to the defendant's mental health).

201 See United States v. Biagon, 510 F.3d 844, 847 (9th Cir. 2007) (holding that, while a defendant does not have "a right to unlimited allocution," “[t]he right to allocution may be satisfied by allowing a defendant an opportunity to make a statement before the end of sentencing but after the court has indicated its tentative conclusions on sentencing”); United States v. Reyna, 358 F.3d 344, 347 (5th Cir. 2004) ("Under the law of this Circuit, the right to allocution applies at sentencing following revocation of supervised release.”).

202 See Green v. Georgia, 442 U.S. 95 (1979) (finding, where a capital defendant was prevented from proffering testimony during the sentencing stage of his trial that "this exclusion violated the Due Process Clause of the Fourteenth Amendment”). But see Oregon v. Guzek, 546 U.S. 517 (2006) (holding that the defendant had no right to present evidence of innocence at his sentencing hearing, where a state statute allowed the defendant to introduce any evidence of his innocence that had been admitted at trial); McGinnis v. Johnson, 181 F.3d 686,693 (5th Cir. 1999) (holding that a defendant's Due Process rights were not violated when hearsay evidence from a psychiatric expert's interview with defendant was excluded during the sentencing phase of a capital case). 
*DRAFT: PLEASE DO NOT CITE WITHOUT PERMISSION

MAY 3, 2013

examine hostile witnesses at non-capital ${ }^{203}$ sentencing hearings, ${ }^{204}$ some state courts have held that the Confrontation Clause of the Sixth Amendment applies to non-capital sentencing proceedings. ${ }^{205}$ Jurisdictions may convey additional rights through rule or common law. ${ }^{206}$ Therefore, in contrast to his situation during intake, a criminal defendant at sentencing would at the very least have an attorney's assistance in gathering evidence of mental disorder and vulnerability, bringing this information to the judge's attention, and arguing that it warrants mitigation (if supported by law). ${ }^{207}$ Moreover, a criminal defendant would have the benefit of a neutral decision-maker whose priority is to determine an appropriate, proportionate, and humane penalty for the offender. ${ }^{208}$

${ }^{203}$ A minority of federal courts have held that defendants have a right to confront adverse witnesses in capital sentencing proceedings. See Proffitt v. Wainwright, 685 F.2d 1227, 1253-54 (11th Cir. 1982) (noting that "[w]hether the right to cross-examine adverse witnesses extends to capital sentencing proceedings has not been specifically addressed by the Supreme Court" and holding that "the right to cross-examine adverse witnesses applies to capital sentencing hearings"); United States v. Mills, 446 F. Supp. 2d 1115, 1131 (C.D. Cal. 2006) (holding that the Confrontation Clause applies during the selection phase and at least part of the eligibility phase of capital sentencing).

${ }^{204}$ See United States v. Paull, 551 F.3d 516 (6th Cir. 2009) (listing cases).

${ }^{205}$ See, e.g., Vankirk v. State, 2011 Ark. 428,*10 (2011) ("[W]e are convinced that the right of confrontation, guaranteed by ... . the Sixth Amendment ... extends to Appellant's sentencing proceeding before a jury.”); State v. Rodriguez, 754 N.W.2d 672, 680-81 (Minn. 2008) (holding that the Sixth Amendment right of confrontation applies during jury sentencing trials); State v. Hurt, 702 S.E.2d 82, 87 (N.C. Ct. App. 2010) (holding that the right to confrontation "applies to all sentencing proceedings where a jury makes the determination of a fact or facts that, if found, increase the defendant's sentence beyond the statutory maximum"); Amanda Harris, Surpassing Sentencing: The Controversial Next Step in Confrontation Clause Jurisprudence, 64 FLA. L. REv. 1447 (2012) (distinguishing between trends in federal and state law and arguing that the right of confrontation should apply during sentencing, or at least during capital sentencing).

${ }^{206}$ See Hessick, supra note 170 , at 1101 n.178 (listing sources of authority).

${ }^{207}$ See id. at 1102-05 (observing that mandatory and discretionary sentencing regimes that explicitly identify relevant aggravating and mitigating factors "provide an easy standard against which to measure counsel's performance at sentencing" and stressing that counsel has a duty to investigate the existence of an available mitigating factor).

${ }^{208}$ Jurisdictions vary in their articulated aims of sentencing, but retributive principles inspire the sentencing codes of many jurisdictions. See Richard Frase, Punishment Purposes, 58 STAN. L. REV. 67, 76 \& n.22 (2005) (claiming that nearly every jurisdiction in the United States has promulgated sentencing codes consistent with Norval Morris's limiting retributivism); Paul H. Robinson, Competing Conceptions of Modern Desert: Vengeful, Deontological, and Empirical, 67 CAMBRIDGE L.J. 145 (2008), available at http://ssrn.com/abstract=924917 ("In the US, a number of sentencing guidelines have adopted desert as their distributive principle, and it is increasingly given deference in the 'purposes' section of state criminal codes, where it can be the guiding principle in the interpretation and application of the code's provisions . . ..”). Contra Michael Tonry, Looking Back to See the Future of Punishment in America, 74 Soc. RESEARCH 353, 363 (2007) ("In this first decade of the twenty-first century, there is neither a prevailing punishment 
Furthermore, the public nature of the proceeding would also impart valuable transparency and accountability to the evaluation process. ${ }^{209}$ Currently, prisons conduct their mental health and vulnerability assessments behind closed doors, so decisions regarding assessment, treatment, and discipline receive little scrutiny. Allowing a judge to factor an individual's mental disorder and vulnerability to harm into sentencing would bring these assessments-and underlying prison conditions - to light and subject them to review and public debate.

\section{B. Comparison to Guilty But Mentally Ill Verdict}

If a judge were able to secure a post-conviction psychiatric evaluation for a seriously disordered prisoner, the judge would be able to effect the primary benefit that a guilty but mentally ill verdict provides for disordered offenders, but in a more appropriate form. While statutes differ, one common formulation of the guilty but mentally ill verdict allows a jury to find a defendant who has asserted an insanity defense "guilty but mentally ill," thus exposing him to any sentence appropriate for the offense but specifying that the defendant is eligible for treatment while incarcerated. ${ }^{210}$ Numerous legal commentators have observed that the guilty but mentally ill verdict has not resulted in better treatment for offenders so designated than for other mentally ill prisoners. ${ }^{211}$ In some states, however, the

paradigm in practice nor a prevailing normative framework for assessing or talking about punishment in principle.”).

209 See Kay A. Knapp, Allocation of Discretion and Accountability Within Sentencing Structures, 64 U. COLO L. REV. 679, 689 (1993) ("[T]he judiciary is the discretionary point that is most accountable. Compared to any other discretionary point-prosecutors, corrections administrators, or parole boards - judicial decisions are public, as is the information on which they base their decisions (open at least to those involved with the case, if not to the public at large). Judges are expected to provide reasons for their decisions and there is a strong tradition of review for most decisions - although not for sentencing decisions. With respect to sentencing under a structured system, judges are experienced in applying general principles, concepts, and standards to particular cases.”).

210 See Christopher Slobogin, The Guilty But Mentally Ill Verdict: An Idea Whose Time Should Not Have Come, 53 GEO. WASH. L. REV. 494, 495 (1984-85).

211 See, e.g., John Q. La Fond \& Mary L. Durham, Cognitive Dissonance: Have Insanity Defense and Civil Commitment Reforms Made a Difference?, 39 VILL. L. REV. 71, 103 (1994) ("Contrary to the expectation that accompanied GBMI legislation, GBMI offenders are no more likely to receive treatment than mentally ill offenders in the general inmate population who have not been found GBMI.”); Lisa A. Callahan, et al., Measuring the Effects of the Guilty but Mentally Ill (GBMI) Verdict, 16 LAW \& HuM. BEHAV. 447, 460 (1992) (“[T]he treatment available to GBMIs is no different from that available to other prisoners with mental health needs.”); Ingo Keilitz, Researching and Reforming the Insanity Defense, 39 RUTGERS L. REV. 289, 319 (1987); Slobogin, Guilty But Mentally Ill Verdict, supra note 210, at 513-14 (identifying legal and fiscal constraints that minimize differences in the treatment afforded to guilty and guilty but mentally ill prisoners). 
*DRAFT: PLEASE DO NOT CITE WITHOUT PERMISSION

MAY 3, 2013

verdict has increased the likelihood that offenders will receive a psychiatric evaluation, thus increasing the odds that their illnesses will be detected, and thus that the inmates ultimately will receive mental health treatment in prison. ${ }^{212} \mathrm{~A}$ judge's finding at sentencing could operate in the same fashion.

Moreover, a judge's finding of mental disorder at sentencing would be more probative, and more appropriate, than the finding of mental disorder communicated through a guilty but mentally ill verdict. Commentators have criticized guilty but mentally ill verdicts on the basis that assessments of mental disorder at the time of the crime are largely irrelevant to a prisoner's mental health needs during confinement. ${ }^{213}$ This objection holds less purchase in the context of sentencing, however, since a sentencing judge's concerns rightfully extend to an inmate's predicted mental health needs in prison, among other issues, $^{214}$ and the judge's assessment takes place shortly before admission to prison.

\section{Sentencing as a Means to Equalize Conditions of Confinement}

Beyond raising an offender's disorder to the attention of correctional officials, legislatures should consider authorizing judges to tailor the carceral sentences of vulnerable, seriously disordered offenders as a means to effectuate proportionate and humane punishment and to equalize, at least in part, the carceral

${ }^{212}$ Slobogin, Guilty But Mentally Ill Verdict, supra note 210, at 514 n.95 (observing that, "[i]n many states, guilty but mentally ill offenders receive post-conviction evaluation more often than do other offenders; therefore, their treatment needs are more likely to be identified); Keilitz, supra note 211, at 319 (concluding, from a review of records from Georgia, Illinois, and Michigan, that at least $90 \%$ of GBMI inmates received a post-conviction mental health evaluation, and that treatment was recommended in 64-72\% of those cases); cf. Linda A. Teplin, Detecting Disorder: The Treatment of Mental Illness Among Jail Detainees, 58 J. Consulting \& CliniCAL PsYCHOL. 233, 234 (1990) (documenting that jail officials treated as "detected" the mental disorder of any detainee evaluated for incompetency to stand trial or not guilty by reason of insanity, regardless of outcome).

${ }^{213}$ Slobogin, Guilty But Mentally Ill Verdict, supra note 210, at 518; Mark A. Woodmansee, The Guilty But Mentally Ill Verdict: Political Expediency at the Expense of Moral Principle, 10 Notre DAme J.L. ETHICs \& PUB. Pol’y 341, 385 (1996) (“Although the jury [in a guilty but not mentally ill case] found evidence of mental illness, this indicates only that the defendant suffered from mental illness at the time of the offense. Such a determination is not dispositive of whether the defendant should receive mental health treatment at the time he is sentenced.”).

${ }^{214}$ A defendant's mental disorder may impact sentencing in several ways. His mental impairment at the time of the crime may serve as a mitigating factor to the extent that it reduces his culpability. In addition, mental illness may aggravate a defendant's sentence, as sentencing bodies appear to assume that mental disorder correlates with dangerousness. See, e.g., Ellen F. Berkman, Mental Illness as an Aggravating Circumstance in Capital Sentencing, 89 ColuM. L. REV. 291, 299-300 (1989) (discussing the use of mental disorder, a mitigating factor, as an aggravating circumstance in capital sentencing). 
*DRAFT: PLEASE DO NOT CITE WITHOUT PERMISSION

MAY 3, 2013

experiences of disordered and standard offenders. ${ }^{215}$ Legislatures possess the inherent authority to designate where offenders will serve sentences of incarceration $^{216}$ and to provide for the proper care and treatment of prisoners. ${ }^{217}$ While in modern history legislatures have tended to delegate the placement authority to prison authorities in recognition of their expertise and need to control housing decisions when managing large numbers of prisoners, ${ }^{218}$ a legislature could instead retain this power ${ }^{219}$ or delegate it to the judiciary. ${ }^{220}$ Furthermore,

${ }^{215}$ See supra notes 184 \& 208 and accompanying text.

${ }^{216}$ See, e.g., State v. Bouck, 633 N.W.2d 163, 165 (N.D. 2001) ("When the law prescribes a place of imprisonment the court cannot direct a different place and, if it does, the sentence is void.”); see infra note 220 (tracing Congress's delegation of the placement authority to the judicial and then executive branches).

${ }^{217}$ See Estabrook v. King, 119 F.2d 607, 610 (8th Cir. 1941) (“Congress undeniably has the power to make provision for the proper care and treatment of federal prisoners during the period of their incarceration, and to set up any form of administrative machinery that it deems necessary for this purpose.”).

218 See, e.g., 18 U.S.C. § 3621(b) (2006) ("The Bureau of Prisons shall designate the place of the prisoner's imprisonment.”); FLA. STAT. ANN. § 20.315(7) (2011) (“The department [of corrections] shall place each offender in the program or facility most appropriate to the offender's needs, subject to budgetary limitations and the availability of space.”); R.I. GEN. LAWS ANN. § 4256-10(13) (2012) (granting the director of the department of corrections the power to "assign or transfer those persons [committed to the custody of the department] to appropriate facilities and programs”); see also McKune v. Lile, 536 U.S. 24, 39 (2002) ("It is well settled that the decision where to house inmates is at the core of prison administrators’ expertise.”).

219 See Bouck, 633 N.W.2d at 165. A recent manifestation of this power is California's "realignment" initiative, under which all felonies that are non-serious and non-violent, including non-registerable sex offenses, are now punishable by incarceration in the county jail, rather than a state prison. See CAL. PENAL CODE $§ 1170(h)(2)-(3)$. For commentary regarding the effects of this initiative, see Emilie A. Whitehurst, Note, Shaping California's Prisons: How the Alternative Custody Program, Designed to Remedy the State's Eighth Amendment Violations in the Prison System, Encroaches on Equal Protection, 21 WM. \& MARY BILL RTS. J. 303, 321-29 (2012) (arguing this initiative violates the Equal Protection Clause); Ken Strutin, The Realignment of Incarcerative Punishment: Sentencing Reform and the Conditions of Confinement, 38 WM. MiTCHELL L. REV. 1313, 1338-39 (2012).

${ }^{220}$ In the early 1800s, Congress authorized federal courts to designate facilities (including state prisons, penitentiaries, and jails) for the execution of federal sentences. See 4 Stat. 118, sect. 15 (1825); 13 Stat. 500 (passed March 3, 1865); Cosgrove v. Smith, 697 F.2d 1125, 1135-36 (D.C. 1983) (tracing this history); Ex Parte Karstendick, 93 U.S. 396, 398-400 (1876) (detailing relevant statutory provisions). During the Civil War, Congress continued this delegation to federal courts, but also authorized the Secretary of the Interior, and then the Attorney General, to assign federal prisoners to state prisons. Cosgrove, 697 F.2d at 1136. The U.S. Supreme Court affirmed that Congress held this authority, Karstendick, 93 U.S. at 401, and recognized that authorizing courts to select sites of confinement might allow for the fine-tuning of offenders' punishments, see id. at 399. In particular, in Ex Parte Karstendick, the Court noted the varying severity of prisons' disciplinary and treatment practices, and approved courts' selection of a particular prison as a means to "graduate" the severity of an offender's sentence. Id. at 399. In 1941, Congress 
*DRAFT: PLEASE DO NOT CITE WITHOUT PERMISSION

MAY 3, 2013

while prison officials should certainly possess broad discretion to run prisons in the manner they see fit, ${ }^{221}$ legislatures should recognize that certain conditions of confinement may be necessary for the incarceration of some offenders with major mental disorders to be humane. In addition to setting standards governing correctional officials' care and treatment of this population, ${ }^{222}$ legislatures should consider authorizing judges to identify particularly vulnerable offenders and to structure these offenders' prison sentences so that they will serve the intended purposes of punishment. ${ }^{223}$

In essence, when a judge believes that a seriously disordered offender should be incarcerated for his crime-but that confinement under certain, predictable conditions would render his punishment excessive, inhumane, or otherwise inappropriate-the judge should be permitted to tailor the sentence so that the offender's actual experience will conform, as closely as possible, to that

eliminated courts' ability to select an offender's facility and transferred this power completely to the Attorney General. See 55 Stat. 252 (1941) (amending 18 USC 753(f)). Currently, 18 U.S.C. § 3621(b) (2012) provides that “[t]he Bureau of Prisons shall designate the place of the prisoner's imprisonment.”

Of course, unless a legislature authorizes the judiciary to select the site of confinement, the place the sentence is executed is not part of an offender's sentence. See Aderhold v. Edwards 71 F.2d 297, 297-98 (5th Cir. 1934 ) ("The sentence in a criminal case fixes the term of punishment, but the law provides for the place of imprisonment. . . . The place of confinement is not part of the sentence.”); Schwab v. Berggren, 143 U.S. 442, 451 (1892) (“[I]t is well settled that the time and place of execution are not, strictly, part of the judgment of sentence, unless made so by statute.”).

${ }^{221}$ See Turner v. Safley, 482 U.S. 78, 84-85 (1987) ("Running a prison is an inordinately difficult undertaking that requires expertise, planning, and the commitment of resources, all of which are peculiarly within the province of the legislative and executive branches of government. Prison administration is, moreover, a task that has been committed to the responsibility of those branches, and separation of powers concerns counsel a policy of judicial restraint."); Jones v. North Carolina Prisoners' Labor Union, 433 U.S. 119, 126 (1977) (“Because the realities of running a penal institution are complex and difficult, we have also recognized the wide-ranging deference to be accorded the decisions of prison administrators.”).

222 See, e.g., Prison Rape Elimination Act of 2003, 42 U.S.C. §§ 15601-15609 (2005) (calling for study of sexual abuse in detention facilities and national standards to prevent, detect, and respond to it); National Standards to Prevent, Detect, and Respond to Prison Rape, Docket No. OAG-131 (signed May 16, 2012) (to be codified at 28 C.F.R. pt. 115), www.ojp.usdoj.gov/programs/pdfs/prea_final_rule.pdf (establishing guidelines for the staffing of detention facilities, the supervision and monitoring of inmates, the classification and housing of inmates within a facility, the means of reporting sexual abuse, and the investigation of reports of abuse); Angela A. Allen-Bell, Perception Profiling and Prolonged Solitary Confinement Viewed Through the Lens of the Angola 3 Case: When Prison Officials Become Judges, Judges Become Visually Challenged, and Justice Becomes Legally Blind, 39 HASTINGS CONST. L.Q. 763, 820 n.296 (2012) (reviewing the efforts of several state legislatures to monitor and restrict the use of solitary confinement, especially for offenders with mental illnesses).

223 See American Bar Association, Criminal Justice System, Project on Standards Relating to the Legal Status of Prisoners, 14 AM. CRIM. L. REV. 377, 408-09 (1977). 
*DRAFT: PLEASE DO NOT CITE WITHOUT PERMISSION

MAY 3, 2013

intended by the judge at the moment of sentencing. Many conditions could be useful to this end and would affect correctional affairs to varying degrees. This Part will assess several possible sentence conditions, including the disqualification or designation of particular facilities and treatment directives. In modifying the carceral sentence of a seriously disordered offender, the goal of the judge would be to mitigate the risks of serious harm that prison poses to the offender, rendering the carceral sentence a humane and proportionate response to the offender's criminal act.

One important caveat is necessary to address at the forefront. Several of the options below affect a prisoner's housing. As referenced previously, correctional agencies typically reach facility and housing placements through a complex classification process. External classification assesses the level of risk posed by an inmate and dictates the amount of supervision the inmate requires. ${ }^{224}$ The risk evaluation considers an inmate's offense, criminal history, past conduct within correctional institutions, and socio-demographic factors (such as age, history of mental illness, and gang affiliation), all of which bear a statistical association with future prison conduct. ${ }^{225}$ These risk factors determine an individual's custody level, which suggests the security level of the appropriate facility for the inmate. ${ }^{226}$ The ultimate facility selected, in addition to offering adequate security, ideally should be capable of providing the treatment and programming that an inmate requires to meet the agency's constitutional obligations and to satisfy the punishment goals for that inmate, such as reducing recidivism. ${ }^{227}$ Security and management considerations drive classification decisions, ${ }^{228}$ and at times an inmate's classification can yield a placement without necessary treatment modalities. ${ }^{229}$ Most prisons allow for "overrides" to change

${ }^{224}$ HARDYMAN ET AL., PRISONER INTAKE Systems, supra note 22, at 57.

225 James Austin, External and Internal Classification, supra note 102, at 6; JAMES AUSTIN, FINDINGS IN PRISON CLASSIFICATION AND RISK ASSESSMENT 2-3, 5 (Nat'l Institute of Corrections 2003), http://static.nicic.gov/Library/018888.pdf.

${ }^{226}$ HARDYMAN ET AL., PRISONER INTAKE SYSTEMS, supra note 22, at 57. For instance, a medium custody offender should be confined in a medium security facility or in a facility with medium security beds.

227 James Austin, External and Internal Classification, supra note 102, at 6 ("[Needs classification] information is used to determine in which programs or special services the inmate should be participate while incarcerated to enhance adjustment to the facility and to reduce the risk of recidivism. When combined with the inmate's custody level, it further refines the decisions surrounding to which facility an inmate will be assigned.”).

228 Holton, supra note 90, at 105 (“[Inmate classification] decisions are typically and primarily based on security or management aspects of behavior (e.g., assault history, escape risk) rather than on clinical need.”).

${ }^{229}$ Id. (observing that "some treatment modalities may not be available at all security levels, so an inmate may be unable to receive optimal care due to his or her security rating”). 
the custody and security of an inmate to accommodate mental health or medical conditions. $^{230}$ One clinical psychologist with experience working within several prison systems observed, however, that the "override" mechanism is inadequate to ensure the provision of clinical placements because "often the decision to apply [the "override"] variable is made by a nonclinical staff member, or factors such as the inmate's criminal or disciplinary history are given more weight than the inmate's need for treatment." ${ }^{231}$ When a judge imposes conditions that affect a defendant's facility or housing placement, the judge should ensure that correctional officials anticipate being able to satisfy these conditions without unduly compromising the institution's legitimate security needs. ${ }^{232}$

\section{A. Authority to Disqualify Certain Facilities}

One option to reduce a vulnerable offender's risk of harm when imprisoned would be to authorize judges to disqualify certain facilities as possible sites of confinement. A judge may find a facility unacceptable for a particular vulnerable, seriously disordered offender on a number of grounds, including the facility's thin mental health staffing, inadequate mental health services, ${ }^{233}$ lack of specialized housing for individuals with serious but non-acute mental disorders, ${ }^{234}$ dearth of protective housing, high rates of violence, or overcrowding. A facility may also be objectionable in light of its regular practice of disciplining or protecting offenders through placement in isolation. ${ }^{235}$ A 2004 report by the National Institute of Corrections indicates that $47 \%$ of states treat offenders with serious mental illnesses as eligible for the same punishments for disciplinary

${ }^{230}$ Anderson, supra note 89, at 222.

${ }^{231}$ Holton, supra note 90, at 105.

${ }^{232}$ See American Bar Association, supra note 223, at 408-09 (proposing the following standard of sentencing court oversight: "Judges should not sentence defendants to confinement unless correctional authorities have certified in writing that facilities, programs, and personnel are available to reasonably carry out the purpose and intent of each sentence.”).

${ }^{233}$ See, e.g., BECK \& MARUSCHAK, supra note 21, at 1-2, 5 (reporting the percentage of state adult correctional facilities that provide 24-hour mental health care, therapy, and medication); Ronald W. Manderscheid et al., Growth of Mental Health Services in State Correctional Facilities 1988 to 2000, 55 Psychiatric Services 869, 871 (2004) (Table 1) (reporting the number and percentage of adult correctional facilities that provide 24-hour mental health care, therapy, and medication in each state).

${ }^{234}$ See infra notes 246-268 (discussing intermediate care facilities).

${ }^{235}$ Several courts have held that the prolonged isolation of offenders with serious mental illnesses constitutes cruel and unusual punishment. See Johnston, Vulnerability, supra note 12, at 178 \& n.156. 
*DRAFT: PLEASE DO NOT CITE WITHOUT PERMISSION

MAY 3, 2013

violations as standard offenders. ${ }^{236}$ In addition, as previously discussed, vulnerable inmates in many prisons are placed in protective custody in extremely restrictive conditions, ${ }^{237}$ which can cause acute psychological deterioration and distress. ${ }^{238}$ Many offenders with serious mental disorders are both vulnerable to abuse and likely to experience difficulty complying with prison rules, ${ }^{239}$ so disqualifying facilities that respond to these foreseeable predicaments in ways that expose inmates to serious risks of harm could serve as an important means to excise those sources of harm most likely to render an offender's sentence disproportionate or inhumane. ${ }^{240}$

This option has several practical limitations, however. While disqualifying a facility for a given prisoner could, in theory, pose minimal difficulty for a correctional agency, that outcome would depend on the number of available facilities and the security levels present within each one. Also, disqualifying any particular facility does not guarantee anything about where or how the offender will actually be confined, so the capacity of this option to improve conditions of confinement for seriously disordered offenders is questionable. Disqualifying certain facilities could even result in greater hardship for a seriously disordered offender if, for instance, he were placed in a facility farther away from his family or support network as a result of this sentence condition.

\section{B. Authority to Designate Certain Facility}

Alternatively, a legislature could grant the judicial branch the authority to order that a vulnerable, seriously disordered offender serve his sentence-or at least start his sentence ${ }^{241}$ —in a particular facility, such as one with certain mental health, programming, or protective resources, assuming that the facility is capable

236 AUSTIN \& MCGINNIS, supra note 41, at 37 ("In 47 percent of the responding states, mentally ill inmates who are disruptive are subject to the same maximum-custody policies as all other inmates.”).

237 See supra note 103.

238 See Johnston, Vulnerability, supra note 12, at $202 \mathrm{nn} .257-59$.

239 See supra notes 91-96 and accompanying text.

240 Some states have taken a similar approach in the context of juvenile delinquents, allowing their transfer to adult correctional facilities but prohibiting their confinement in certain prisons. See IND. CODE § 11-10-2-10(a)(3) (1998) (authorizing the commissioner of corrections to transfer a committed delinquent offender to an adult facility or program in certain circumstances, but providing that "[n]o offender may be transferred to the Indiana state prison or the Pendleton Correctional Facility”).

${ }^{241}$ See text accompanying note 273, infra. Multiple considerations militate toward allowing prison officials to transfer prisoners among facilities, such as prisoners' evolving mental health statuses, the need to protect prisoners from dangers within a particular facility, changes in prisoners' security classifications, and institutional priorities and resource needs. 
*DRAFT: PLEASE DO NOT CITE WITHOUT PERMISSION

MAY 3, 2013

of managing an offender's security risks. ${ }^{242}$ For instance, a legislature could establish that seriously disordered offenders who would face unacceptable levels of hardship in a typical prison facility should serve their sentences in a correctional facility capable of offering an appropriate therapeutic environment, and then grant sentencing judges the authority to identify vulnerable individuals and select available facilities that comply with this directive in a given case. Some prisons, for instance, offer intermediate care facilities or residential treatment units, which have been shown to "dramatically improve the quality of life" of mentally ill inmates who have difficulty coping with the stresses of prison, especially those who are vulnerable to predatory inmates in the general prison population or who struggle with medication compliance. ${ }^{243}$ While ordering the confinement of a vulnerable, seriously disordered offender in a facility with certain treatment or protective resources would not guarantee access to those services for the duration of an offender's sentence, ${ }^{244}$ residence may increase the likelihood of an offender's receipt of those resources if the need arises, as long as they are available at the offender's security level. ${ }^{245}$

\section{Intermediate Care Facilities}

While commentators have almost universally characterized prison as a toxic environment for individuals with serious mental illnesses, ${ }^{246}$ an exception exists for those individuals housed in intermediate care facilities, also known as residential treatment units. Intermediate care facilities, which exist in a slowly increasing number of states, ${ }^{247}$ are designed to provide a stable and therapeutic environment for mentally ill prisoners ${ }^{248}$ who are unable to cope effectively in the

242 See supra notes 224-232 and accompanying text.

243 Fred Cohen \& Joel Dvoskin, Inmates with Mental Disorders: A Guide to Law and Practice, 16 MENTAL \& PhysiCAL DisABILITY L. REP. 401, 465 (1992).

${ }^{244}$ Intermediate care "facilities" are often units within larger facilities. See infra note 252.

245 See Holton, supra note 90, at 105 (observing that “some treatment modalities may not be available at all security levels, so an inmate may be unable to receive optimal care due to his or her security rating”).

246 See supra note 137.

247 See supra notes 117-128.

${ }^{248}$ Many intermediate care programs focus on treating prisoners with severe mental illnesses. See, e.g., David Lovell et al., Evaluating the Effectiveness of Residential Treatment for Prisoners with Mental Illness, 28 CRIM. JUST. \& BEHAV. 83, 86 (2001); OHIO DRC, supra note 119, at 2. Inmates with less serious disorders but with significant coping problems are also eligible in some states. OHIO DRC, supra note 119, at 2; Ward S. Condelli et al., Intermediate Care Programs for Inmates with Psychiatry Disorders, 22 Bull. AM. ACAD. Psychiatry LAW 63, 67 (1994) (Table 2) (listing psychiatric diagnoses of inmates in intermediate care programs). 
*DRAFT: PLEASE DO NOT CITE WITHOUT PERMISSION

MAY 3, 2013

general prison population but do not require hospital-level care. ${ }^{249}$ Modeled on the "therapeutic community" and "therapeutic milieu” concepts advanced by Hans Toch and his colleagues, ${ }^{250}$ intermediate care facilities provide inmates with a therapeutic environment that reduces the stressors and conditions that cause psychological degeneration and threaten victimization. As described by Professor David Lovell, these programs "operate on the premise that, like some other disabilities, mental illness may not be curable, but persons with mental illness can cope with the disability if provided with effective clinical care and equipped with the needed understanding and skills." ${ }^{251}$ Within these units or facilities, ${ }^{252}$ many treatment modalities and programming options are typically available. ${ }^{253}$ Prisoners, through individual or group therapy, may learn symptom recognition, anger management, medical compliance strategies, communication techniques, and vocational skills. ${ }^{254}$ Rates of medication compliance are high as a result of patient education, symptom management, frequent psychiatric consultations, and

249 Human Rights WATCh, supra note 33, at 130; CORRECTIONAL AsSOCIATION OF NEW YORK, supra note 90, at 35; VIRGINIA DEPARTMENT OF CORRECTIONS, supra note 109, at 2; OHIO DRC, supra note 119, at 2; WASHINGTON DEPARTMENT OF CORRECTIONS, supra note 118, at 3.

250 See generally THERAPEUTIC COMMUNITIES IN CORRECTIONS (Hans Toch, ed. 1984).

${ }^{251}$ Lovell et al., supra note 248 , at 86.

${ }^{252}$ Intermediate care facilities may reside within a separate correctional mental health facility or in separate wards or units within individual prisons. For example, New York operates intermediate beds within eleven of its maximum security prisons. CORRECTIONAL ASSOCIATION OF NEW YORK, supra note 90, at 35 (stating that each residential treatment unit has its own cellblock with separate areas of programming and recreation and characterizing these units as "islands of compassionate care in the stressful and sometimes violent world of maximum-security prisons"). Washington provides residential treatment in three facilities, including the McNeil State Prison. WASHington DEPARTMENT OF CORRECTIONS, supra note 118, at 4. Kansas maintains a separate mental health facility. See LARnEd CORREctional MENTAL HeAlth FACiLity, supra note 122. Security levels vary amongst institutions, and even within a single program. See, e.g., OHIO DRC, supra note 119, at 4-5 (providing a summary of the treatment, housing, and therapy offered at the four levels of its intermediate care program); VERMONT DEPARTMENT OF CORRECTIONS, supra note 125, at 2 (offering a secure residential treatment program for the psychiatric treatment of inmates with close custody needs and an intermediate residential treatment program whose goal is to "provide transitional mental health care to . . . prepare [inmates] for successful reintegration into the general inmate population”); Kupers et al., supra note 124, at 1042 (describing Mississippi’s program, which divides its inmates into two blocks, one upper level where inmates are segregated, but receive intensive treatment and therapy, and one lower level open unit, resembling the general population).

${ }^{253}$ See, e.g., CORRECTIONAL Association OF NEW YORK, supra note 90, at 35; Lovell et al., supra note 248, at 86; Kupers et al., supra note 124, at 1042-43; Condelli et al., supra note 248, at 64.

254 See, e.g., CORRECTIONAL Association OF NEW YoRK, supra note 90, at 35; Lovell et al., supra note 248, at 86; Kupers et al., supra note 124, at 1042-42; MacKain \& Messer, supra note 120, at 92, 96. 
the increased privacy and decreased stigma afforded to receipt of psychotropic medication in these units. ${ }^{255}$ Much like a halfway house or community care center outside prison, these units are intended as short- or mid-term safe-havens where inmates learn strategies for living in the larger "community," or the general prison population. ${ }^{256}$ While programs encourage re-entry to the general population, some administrators allow inmates to remain in residential treatment units if re-entry is not feasible given an inmate's risk of victimization, self-harm, or medication noncompliance. $^{257}$

Multiple studies demonstrate that treatment in intermediate care facilities results in lower levels of mental disorder, disciplinary violations, and victimization, and may yield aggregate cost savings for prisons. ${ }^{258}$ A study by Lovell and his colleagues of the McNeil program in Washington reported:

Inmates were significantly more stable in terms of psychiatric symptoms when they left than when they arrived. Inmates had better infraction records and consumed less of the department's management resources, . . . and were able to maintain themselves in [the] general population setting. ${ }^{259}$

${ }^{255}$ See CORRECTIONAl AsSOCiATION OF NEW YoRK, supra note 90, at 36 (reporting that 95\% of inmates in intermediate care programs (ICPs) said that they take their mediation regularly and $75 \%$ said it was "easier to take medication in the ICP").

256 See, e.g., Kupers et al., supra note 124, at 1042; VERMONT DEPARTMENT OF CORRECTIONS, supra note 125, at 2 ("[The] programs are designed to . . . prepar[e] for and enhanc[e] productive participation in Departmental programs and activities in the general population"); CORRECTIONAL ASSOCIATION OF NEW YORK, supra note 90, at 37; WASHINGTON DEPARTMENT OF CORRECTIONS, supra note 118, at 3.

${ }^{257}$ Intermediate care programs vary in duration. In Washington, , inmates spend a median of seven months in the McNeil mental health program. Lovell et al., supra note 248, at 88. Prison rules specify that prisoners may stay a maximum of eighteen months, but staff allow some inmates to stay longer if they believe no other situation is suitable. Id. In Mississippi, the average stay is three to six months. Kupers et al., supra note 124, at 1043. In New York, inmates may stay in intermediate care programs for years, and "many" never leave. CORRECTIONAL AssOCIATION OF NEW YoRK, supra note 90, at 38; see Condelli et al., supra note 248, at 65. In North Carolina, most offenders complete the Social Skills Training Day Program in six to eight months, but offenders may remain in the program indefinitely if they are "not yet ready for transfer to a less restrictive environment." MacKain \& Messer, supra note 120, at 94.

${ }^{258}$ See MacKain \& Messer, supra note 120, at 91-92 (describing studies).

${ }^{259}$ Lovell et al., supra note 248, at 100. That study measured the number of disciplinary infractions that program participants received before and after completion, and related that figure to a cost index. Id. at 90 . 
*DRAFT: PLEASE DO NOT CITE WITHOUT PERMISSION

MAY 3, 2013

The study also found that inmates consumed fewer prison resources after completing the McNeil program. ${ }^{260}$

Other studies have reached similar conclusions. A 2004 report by the New York Correctional Association found that the intermediate care programs in that state function successfully as a safe haven for mentally ill prisoners. ${ }^{261}$ A survey of intermediate care program inmates revealed that $50 \%$ of inmates had been victimized before entering the program, ${ }^{262}$ and $57 \%$ of inmates did not feel safe in the general population. ${ }^{263}$ A majority of inmates indicated that the intermediate care program successfully protects them from aggressive inmates, and $89 \%$ of surveyed inmates articulated a desire to remain in the program for the duration of their prison sentences. ${ }^{264}$ The rate of inmates' disciplinary infractions also dropped significantly while in the program. ${ }^{265}$ An earlier study in New York found significant reductions in mental health services received by program inmates, including crisis care, seclusion, and hospitalization. ${ }^{266}$ Finally, a study by Terry Kupers and his colleagues of the "step-down" unit in Mississippi's converted super-maximum security prison, Unit 32, found that rates of disciplinary infractions dropped significantly when inmates entered the step-down program (as compared to rates six months prior to entry) and remained depressed six months after the program's completion. ${ }^{267}$ The study concluded: "[I]t is obvious to custody and staff that participation in the step-down unit has helped to keep this group out of trouble."268 Other social scientists have speculated that intermediate care programs may help disordered inmates "generalize the skills

${ }^{260}$ Id. at 96 (Table 4). The finding that intermediate care facilities may convey cost savings might be counterintuitive, since these units typically require more mental health professionals, nurses and counselors per inmate than units in the general population. See, e.g., ALABAMA DEPARTMENT OF CORRECTIONS, supra note 126, at 4 (listing members of an inmate's treatment team).

${ }^{261}$ CORReCtional Association OF NEW York, supra note 90, at 37-38.

${ }^{262}$ Id. at 37 (this figure includes both property offenses and physical victimization).

${ }^{263} \mathrm{Id}$.

${ }^{264} \mathrm{Id}$.

${ }^{265}$ Id. at 38-39; cf. Condelli et al., supra note 248, at 67 (reporting significant reductions in very serious infractions and suicide attempts but not in merely serious infractions, during the six months after admission to the intermediate care program).

${ }^{266}$ Condelli et al., supra note 248, at 68.

${ }^{267}$ Kupers et al., supra note 124, at 1046 (finding that prisoners averaged 4.7 rules violations in the six months before they entered the program, 1.2 violations while in the step-down unit, and 0.6 violations in the six months after the completion of the program).

${ }^{268}$ Id. at 1046. 
*DRAFT: PLEASE DO NOT CITE WITHOUT PERMISSION

MAY 3, 2013

they will need post-release and, therefore, offer promise in reducing stress and cost in a larger sphere of mental health treatment."269

\section{Benefits of Initial Facility Designation}

These studies suggest that intermediate care facilities and residential treatment units offer a humane and affordable ${ }^{270}$ means of confining vulnerable offenders with serious mental illnesses. Governors should allocate funding for expanding these facilities, and legislatures should consider authorizing judgeswhen they find that an offender with a serious mental illness would be unable to cope effectively or would be particularly prone to victimization in the general prison population - to sentence an offender to confinement in a facility with residential treatment units, assuming that such a facility is consistent with an offender's security and management needs. While laws in every jurisdiction provide for the treatment of prisoners with serious mental disorders, ${ }^{271}$ correctional authorities may be unlikely to transfer an offender to a specialized correctional facility or mental hospital until an offender is in acute distress. Authorizing judges to sentence vulnerable, seriously disordered offenders to facilities with intermediate care services should increase the likelihood that correctional officials will move these offenders to those units if the offenders prove unable to cope effectively in the general population. ${ }^{272}$ In essence, it is easier to move an offender within a facility than between facilities, and authorities may be more likely to view intermediate care as a viable option when it is available in the facility in which an inmate resides.

Another option would be to authorize judges to order an offender presumptively to begin his sentence in a particular unit within a given facility, again so long as that placement is consistent with an offender's security needs. Permitting a judge to order that a vulnerable, seriously disordered offender start his carceral term in a residential treatment unit, for instance, would ensure that the offender would receive a comprehensive evaluation, diagnosis, and treatment plan. In addition, residing in an intermediate care facility for a few months would allow an offender to acclimate to any newly administered psychotropic medication, receive greater monitoring of his medication, benefit from individual and group therapy, and develop skills and strategies for living in the general prison population, such as symptom recognition, anger management, medical

${ }^{269}$ MacKain \& Messer, supra note 120, at 89.

270 See supra note 259-260 and accompanying text.

271 Christopher Slobogin, Arti Rai \& Ralph Reisner, LAW AND the Mental HeAlth SYSTEM 640 (5th ed. 2009).

${ }^{272}$ While this statement is intuitive, empirical research is necessary to verify its accuracy. 
*DRAFT: PLEASE DO NOT CITE WITHOUT PERMISSION

MAY 3, 2013

compliance, and interpersonal skills. ${ }^{273}$ The individual would thus be better equipped, when (and if) he is transferred out of the unit, to cope successfully in the general population. The individual might also be less likely to fall through the cracks of the prison's mental health care docket if his mental health later deteriorates. Because this would be a presumptive placement, the offender could begin his term in another unit if, in the opinion of a qualified mental health professional, another prison environment could satisfy an offender's treatment and protective needs. ${ }^{274}$ To ensure that the presumption has teeth, the judge could require that correctional officials provide a written explanation for any alternative placement.

\section{Objections}

While this option may result in a higher level of mental health care and a more protective and therapeutic environment for a vulnerable, seriously disordered offender, valid objections could be raised against allowing judges to tailor an offender's sentence in this way. Most obviously, placing individuals first in line for residential treatment slots may result in inequity and a misallocation of resources, as correctional officials would be unable to assign the neediest and most vulnerable offenders to these units. It also may result in designated offenders receiving more costly housing (through service provision or intensive mental health staffing) than is necessary given their current mental health statuses. However, treating a judge's housing placement as rebuttable may respond adequately to these concerns.

Other objections may be harder to diffuse. Allowing judges to make facility designations would impede correctional authorities' abilities to forecast prison housing and resource needs. Given the number of offenders with serious mental illnesses entering the prison system, ${ }^{275}$ allowing judges to order a subset of these offenders to begin their sentences in residential treatment units might require an expansion of those units. ${ }^{276}$ Furthermore, this option would provide only temporary relief to vulnerable, seriously disordered offenders, since correctional officials would be free to transfer the inmates out of these therapeutic environments after some period of time. ${ }^{277}$ As an alternative, a legislature could

273 Over a third of inmates in North Carolina’s Social Skills Day Training Program arrive directly after entering the prison system. See MacKain \& Messer, supra note 120, at 93, 96.

${ }^{274}$ See supra note 188.

275 See supra note 1.

276 Many mental health experts, organizations, and advocates urge states to expand the number and capacities of intermediate care facilities. See, e.g., CORRECTIONAL AsSOCIATION OF NEW YoRK, supra note 90, at 40; HumAN Rights WATCH, supra note 33, at 133-34; Holton, supra note 90 , at 116 .

${ }^{277}$ See supra note 257 (discussing the average length of stay in intermediate care facilities). 
*DRAFT: PLEASE DO NOT CITE WITHOUT PERMISSION

MAY 3, 2013

consider authorizing judges to order that vulnerable, seriously disordered offenders preemptively spend the entirety of their carceral terms in such protective, therapeutic units, at least in states where such a long-term option exists. ${ }^{278}$

\section{Authority to Mandate Certain Treatment Consequences}

Alternatively, a legislature could authorize a judge to attach certain treatment conditions to the carceral sentences of vulnerable, seriously disordered individuals. ${ }^{279}$ In this situation, correctional authorities would retain the ultimate housing decision, but qualifications would govern their treatment of an offender. As with housing stipulations, a judge may want to receive certification from correctional officials that they are able to satisfy a set of conditions before issuing a sentence. ${ }^{280}$ A number of conditions are possible. For instance, a judge could order that, assuming an offender's mental health problems merit treatment, ${ }^{281}$ the offender receive an individualized treatment plan within a designated period of time and treatment in accordance with that plan, plus additional treatment as necessary, over the course of his confinement. The court could require periodic assessments of the nature and extent of the defendant's mental illness and updates regarding the offender's mental health, his housing, and the treatment afforded to him. $^{282}$

${ }^{278}$ But see supra note 241 (listing considerations supporting correctional officials' abilities to transfer inmates among facilities). Future work will assess whether states should segregate all offenders with serious mental illnesses - or only the subset who are particularly vulnerable to serious harm if incarcerated with the general prison population-in designated facilities, as some correctional institutions do for other vulnerable groups, such as gay, trans-women, elderly, and juvenile offenders.

${ }^{279}$ See American Bar Association, supra note 223, at 408-09. Some statutes allow judges to secure commitments from correctional authorities regarding conditions of confinement in the context of proceedings involving juveniles. See, e.g., Michigan MCR 5.956 (1998) (authorizing a judge, in response to a juvenile offender's violation of probation under an order of disposition delaying imposition of sentence, to order a range of sanctions including incarceration for up to 30 days so long as "the present county jail facility would meet all requirements under federal law and regulations for housing juveniles and . . . the court has consulted with the sheriff to determine when the sentence will begin to ensure that space will be available for the juvenile" and specifying that, "[i]f the juvenile is under seventeen (17) years of age, the juvenile must be placed in a room or ward out of sight and sound from adult prisoners; other participation or performance as the court considers necessary”).

${ }^{280}$ See supra note 279.

${ }^{281}$ This determination would ultimately reside with the mental health professional available to assess and treat the inmate inside the prison. See supra note 188.

${ }^{282}$ In this way, sentencing conditions could mimic the requirements of some guilty but mentally ill statutes. See, e.g., 730 ILCS 5/5-2-6 ("If the court imposes a sentence of imprisonment upon a defendant who has been found guilty but mentally ill, the defendant shall be committed to 
*DRAFT: PLEASE DO NOT CITE WITHOUT PERMISSION

MAY 3, 2013

In an attempt to mitigate the risk of serious harm that imprisonment poses to a seriously disordered offender, a judge may wish to add other conditions to his sentencing order. For instance, a judge may want to direct correctional officials to consider the offender's mental disorder, and its possible contribution to a disciplinary violation, in any future disciplinary proceedings. ${ }^{283}$ A judge could order that, in imposing sanctions for future rules violations, officials use their best efforts to avoid imposing sanctions, such as prolonged isolation, known to exacerbate the offender's disorder. ${ }^{284}$ In addition, the sentencing order could provide that, if solitary confinement is deemed absolutely necessary as a security measure, correctional authorities must isolate the offender under conditions outlined by the American Psychiatric Association, which include standards for provision of care, regular assessment by qualified mental health professionals, and removal from segregation of inmates in current, severe psychiatric crisis. ${ }^{285} \mathrm{~A}$ judge could also order that, if an inmate needs to be removed from the general population for his protection, he should be housed in an environment meeting certain programming, treatment, and socialization thresholds in order to preserve the inmate's mental health.

These conditions could be enforced in various ways. Depending on a state's resentencing statute, an offender may be able to move for sentence modification when correctional authorities fail to satisfy a condition of his

the Department of Corrections, which shall cause periodic inquiry and examination to be made concerning the nature, extent, continuance, and treatment of the defendant's mental illness. The Department of Corrections shall provide such psychiatric, psychological, or other counseling and treatment for the defendant as it determines necessary.”).

${ }^{283}$ For example, a judge could mandate that a clinician review any disciplinary reports to discern whether mental disorder contributed to the infraction. Cf. Ball, supra note 39, at 38-39 (noting that, in California, a clinician must review the disciplinary report of every prisoner receiving mental health treatment to determine whether the prisoner's mental disorder contributed to the infraction); AMERICAN PSYCHIATRIC AsSOCIATION, supra note 29, at 26 ("It is especially important to have clinical input when decisions are made about an inmate who is receiving mental health care regarding disciplinary issues, work and housing assignments, and transfers in and out of the institution.”). Prisons vary in the extent to which they consider mental disorder in disciplinary proceedings. See HuMAN Rights WATCH, supra note 33, at 62-64; Michael Krelstein, The Role of Mental Health in the Inmate Disciplinary Process: A National Survey, 30 J. AM. ACAD. PsYCHIATRY L. 488, 494 (2002), available at http://www.jaapl.org/cgi/reprint/30/4/488.

${ }^{284}$ See supra note 95-96 and accompanying text.

285 AMERICAN PSYCHIATRIC AssOCIATION, supra note 29, at 5; see also Cohen \& Dvoskin, supra note 243, at 470 (recommending at least two hours each day of on-site mental health professional staff in an isolation unit); see also Fellner, Corrections Quandary, supra note 39, at 411 ("Most importantly, corrections officials must develop options for responding to dangerous or disruptive individuals who are mentally ill other than simply putting them into segregation. If such individuals require extensive security precautions, they should be housed in specialized secure units where they can participate in purposeful activities, have human interaction, and receive the services that mental health professionals deem therapeutically appropriate.”). 
*DRAFT: PLEASE DO NOT CITE WITHOUT PERMISSION

MAY 3, 2013

sentence. $^{286}$ Alternatively, the legislature could authorize judges to exercise continuing jurisdiction over the sentences of particularly vulnerable offenders with serious mental illnesses, much as judges do over probationers or children and incompetent persons in guardianship proceedings. ${ }^{287}$

\section{Conclusion}

At sentencing, a judge can often foresee that an individual, given his major mental disorder and other vulnerabilities, will experience serious psychological or physical harm in prison. These harms may include psychological deterioration and mental distress, attempted suicide, and victimization by staff or other inmates. In an attempt to reduce the disproportionate effect of incarceration on vulnerable individuals, many jurisdictions designate extreme offender hardship as a mitigating factor for use at sentencing. In these jurisdictions, vulnerability to harm may militate toward an order of probation or a reduced term of confinement. These measures, while salutary, do not go far enough to protect vulnerable offenders who must serve time in prison, however. To ensure that sentences are humane, proportionate, and appropriate to effectuate the intended aims of punishment, legislatures should authorize judges to tailor the conditions of vulnerable, disordered offenders' sentences. Sentencing conditions could include ensuring that offenders receive timely and periodic evaluations by qualified mental health professionals, disqualifying facilities with insufficient mental health or protective resources, specifying the facility or unit where an offender will serve or begin his sentence, or mandating certain treatment in prison. By conditioning vulnerable, disordered offenders' sentences in these ways, judges will be better equipped to individualize offenders' sentences so that sentences both reflect offenders' deserved punishment and avoid cruelty that cannot be condoned by a civilized system of justice.

\footnotetext{
${ }^{286}$ See Schlabach v. State, 37 So.3d 230, 237 (Fla. 2010) (observing with approval judge’s decision to grant a sentence modification where the presence of a substance abuse program was a factor in the judge's original sentence and was not made available to the offender).

287 See American Bar Association, supra note 223, at 584 ("The sentencing court should have a continuing responsibility to insure that its sentence is appropriately carried out. . . The exercise of continuous jurisdiction by the sentencing court is not a stark departure from analogous areas. In guardianship cases, courts often exercise responsibility through appointed agents over children and incompetents. And, even in the criminal area, a sentence to probation is presently subject to continuous review by a sentencing court.”).
} 